University of Nebraska - Lincoln

DigitalCommons@University of Nebraska - Lincoln

10-16-2008

\title{
NEW GENERIC SYNONYMS IN THE ORIENTAL FLEA BEETLES (COLEOPTERA: CHRYSOMELIDAE)
}

Alexander S. Konstantinov

Kaniyarikkal Divakaran Prathapan

Follow this and additional works at: https://digitalcommons.unl.edu/usdaarsfacpub

This Article is brought to you for free and open access by the U.S. Department of Agriculture: Agricultural Research Service, Lincoln, Nebraska at DigitalCommons@University of Nebraska - Lincoln. It has been accepted for inclusion in Publications from USDA-ARS / UNL Faculty by an authorized administrator of DigitalCommons@University of Nebraska - Lincoln. 


\title{
New Generic Synonyms in the Oriental Flea Beetles (Coleoptera: Chrysomelidae)
}

\author{
A. S. Konstantinov \\ Systematic Entomology Laboratory, USDA \\ c/o Smithsonian Institution P.O. Box 37012 \\ National Museum of Natural History \\ MRC-168 Washington, D.C. 20013-7012, U.S.A. \\ alex.konstantinov@ars.usda.gov \\ AND \\ K. D. Prathapan \\ Department of Entomology \\ Kerala Agricultural University \\ Vellayani P.O. \\ Trivandrum - 695 522, Kerala, INDIA \\ prathapankd@gmail.com
}

\begin{abstract}
The following new synonyms are proposed for the genera and species of flea beetles predominantly from the Oriental Region: Pseudocrypta Medvedev, 1996 and Sebaethiella Medvedev, 1993 = Acrocrypta Baly, 1862; Bhutajana Scherer, $1979=$ Aphthona Chevrolat, 1836; Burmaltica Scherer, 1969 = Aphthonaltica Heikertinger, 1924; Aphthonomorpha Chen, 1934 and Manobidia Chen, 1934 = Bikasha Maulik, 1931; Garuda Scherer, $1969=$ Chalaenosoma Jacoby,1893; Priostomus Jacoby, 1884 = Chaloenus Westwood, 1862; Throscoryssa Maulik,1928 = Clitea Baly, 1877; Eucyclomela Chen, 1934 and Schenklingia Csiki \& Heikertinger, $1940=$ Halticorcus Lea, 1917; Luperaria Medvedev, $1993=$ Laboissierella Chen, 1933; Lipraria Medvedev, 1990 = Lipromela Chen, 1933; Asiorella Medvedev, 1990 = Liprus Motschulsky, 1860; Docemasia Jacoby, 1899 = Luperomorpha Weise, 1887; Ceylonaltica Doeberl, 1996 and Mesopa Jacoby, 1903 = Micraphthona Jacoby, 1900; Martensomela Medvedev, 1984 and Nepalicrepis Scherer, $1969=$ Microcrepis Chen, 1933; Nepalicrepis darjeelingensis Scherer, $1969=$ Microcrepis politus Chen, 1933; Epithrella Medvedev, 1993 and Livoliella Medvedev, 1997 = Orthaltica Crotch, 1873; Chabriosoma Chen, 1934 = Phygasoma Jacoby, 1898; Letzuana Chen, 1934 = Phyllotreta Chevrolat, 1836; Kimotoa Gruev, 1985 = Sphaeroderma Stephens, 1831; Amydus Chen, 1935, Monodaltica Bechyne, 1955, Trachyaphthona Heikertinger, 1924, and Typhodes Samuelson, 1984 = Trachytetra Sharp, 1886. Habitus and/or other morphological structures are illustrated for each genus under consideration.

The following new names are proposed: Aphthona gerhardi new name for Aphthona nepalensis (Scherer 1989); Lanka philippina new name for Horaia bicolor (Medvedev 1993); Lanka ogloblini new name for Horaia fulva (Medvedev 1993).

The following new combination is proposed: Manobia nigra (Scherer 1969).
\end{abstract}

Oriental flea beetles have been studied as long as flea beetles of any other zoogeographic region. Currently about 2,500 species have been described. They were originally placed in 302 genera, of which 220 currently are considered valid. Significant authors who described most of the generic diversity are: S. Chen - 43 genera, M. Jacoby - 43 genera, L. Medvedev - 41 genera, J. Weise - 14 genera, J. Baly - 19 genera, S. Maulik - 13 genera, and G. Scherer - 12 genera. Other 
important authors are S. Kimoto (6 genera) and A. Samuelson (7 genera). Apparently, authors who produced less monographic, synthetic works of large faunas described many more genera than those who were involved with keys and revisions on a large scale, such as A. Samuelson (1973) who revised the flea beetles of Oceania and G. Scherer (1969) who treated the flea beetles of India. Analyses of large faunas stimulate a comparative approach, which helps to look for similarities and limits a descriptive urge which often places large and complex faunas in a state of chaos.

The flea beetles of the Oriental Region are in such a state of chaos. During an ongoing revision of the Oriental flea beetle genera, we examined a number of the type species as well as several representatives of many genera. This resulted in many synonyms that we are proposing below. Overall, it appears that there are two main categories of synonyms. The most common synonyms are the ones that are results of clear mistakes. In these cases a known taxon, being unfamiliar to an author, is described for the second time (for example, Docemasia Jacoby, Asiorella Medvedev, Dentisterna Medvedev). In other instances authors wrongly interpreted characters [for example, in describing Aphthonaria, Medvedev (1990) stated that, unlike Aphthona, it has the third metatarsomere entire, however the third metatarsomere in Aphthona is entire (Konstantinov 1998)]. The other kind of synonyms is not immediately obvious. They are the result of misinterpretation of characters and become obvious in a course of revisionary work that attempts to put generic classification in order. They require some changes in the generic concept and reevaluation of several characters that are used to separate flea beetle genera throughout the World and in the Oriental Region in particular. As a result, characters that vary greatly among species of large genera are not used to characterize genera, and the generic classification becomes more logical and user friendly.

Dissecting techniques and terminology follow Konstantinov (1998). The beetles are deposited in the following collections: The Natural History Museum, London, U.K. (BMNH); Bishop Museum, Honolulu, Hawaii, USA (BPBM); Museum of Comparative Zoology, Cambridge, Massachusetts, USA (MCZC); Museum National d'Histoire Naturelle, Paris, France (MNHN); Natural History Museum, Basel, Switzerland (NHMB); Natural History Museum, Geneva, Switzerland (NHMG); Private collection of L. Medvedev, Moscow, Russia (LMCM); Private collection of K. D. Prathapan, Trivandrum, India (PKDC); Senckenberg Museum, Frankfurt am Main, Germany (SMFD); Staatliches Museum fur Naturkunde, Stuttgart, Germany (SMNS); National Museum of Natural History, Smithsonian Institution, Washington D. C. (USNM).

\section{Acrocrypta Baly, 1862}

(Figs. 1-6)

Acrocrypta Baly, 1862: 457 (type species Acrocrypta mouhoti Baly, 1862 by original designation).

Pseudocrypta Medvedev, 1996: 78 (type species Pseudocrypta nigripennis Medvedev, 1996 by original designation). New synonym

Sebaethiella Medvedev, 1993a: 16 (type species Sebaethiella mindanaica Medvedev, 1993 by original designation). New synonym

Describing Acrocrypta, Baly compared it to Acroleuca Chevrolat and distinguished it by "the shorter, more robust and much more dilated antennae, and ... the almost globular maxillary palpi, with their extremely short and nearly 


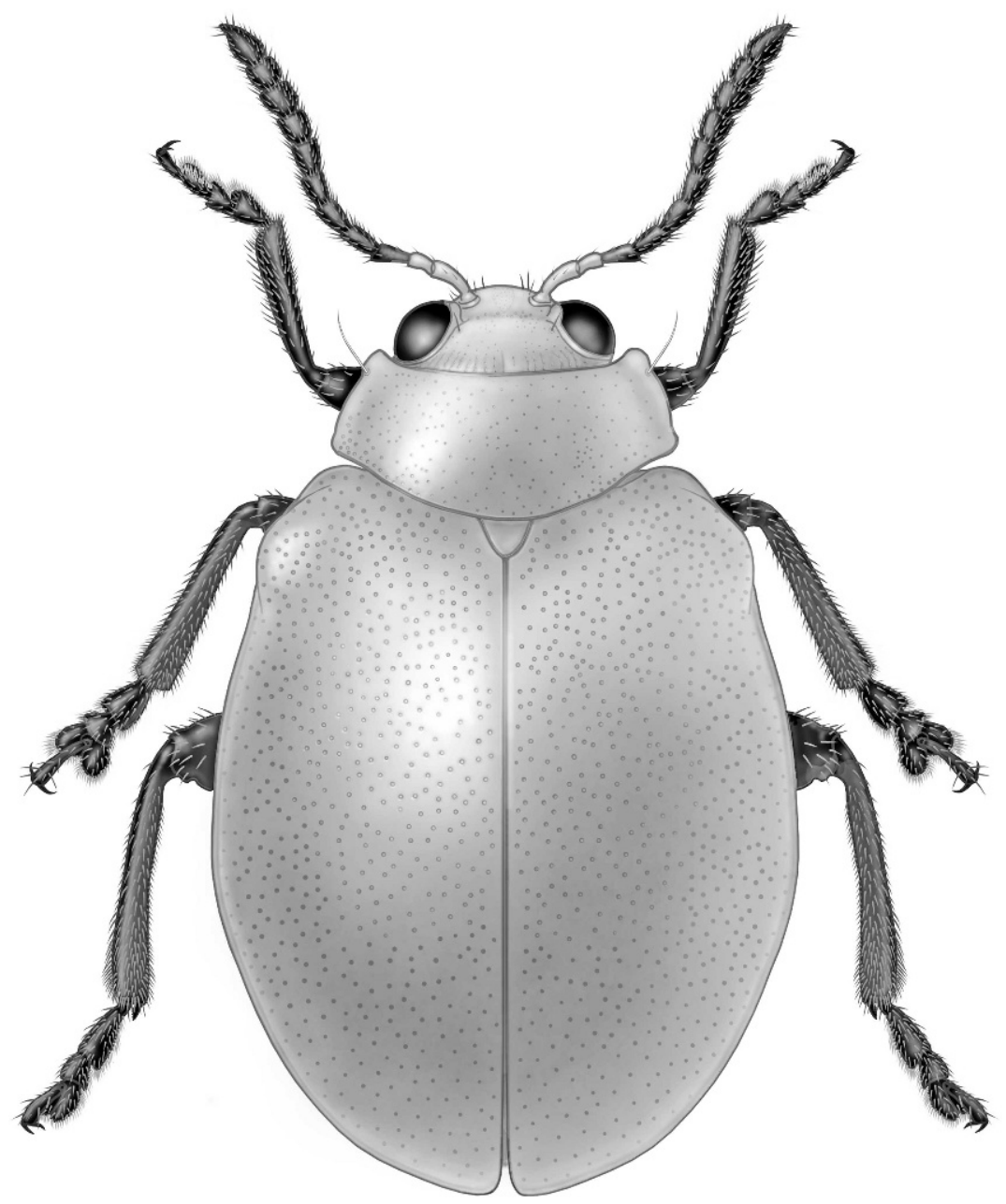

Fig. 1. Acrocrypta mouhoti, habitus.

hidden terminal joint." He proposed two species from Cambodia, the type $A$. mouhoti and $A$. dimidiata Baly.

Proposing Sebaethiella, Medvedev (1993a) compared it with Acrocrypta but provided no features to distinguish them, except that it has the "general appearance of Sebaethe." He also noted that "one of the species described below is transitional between this new genus and Acrocrypta...."

Proposing Pseudocrypta, Medvedev (1996) wrote a short key to separate it from Acrocrypta and Sebaethiella. Two characters are involved in separation of these genera: width of the frontal ridge ("wide," antennal calli separated in Acrocrypta and "narrow," antennal calli attingent in Pseudocrypta and Sebaethiella), and relative length of basal antennomeres 2, 3, and 4 (antennomere 4 about twice as long as 2 and 3 combined in Pseudocrypta and antennomere 4 as long as 2 and 3 

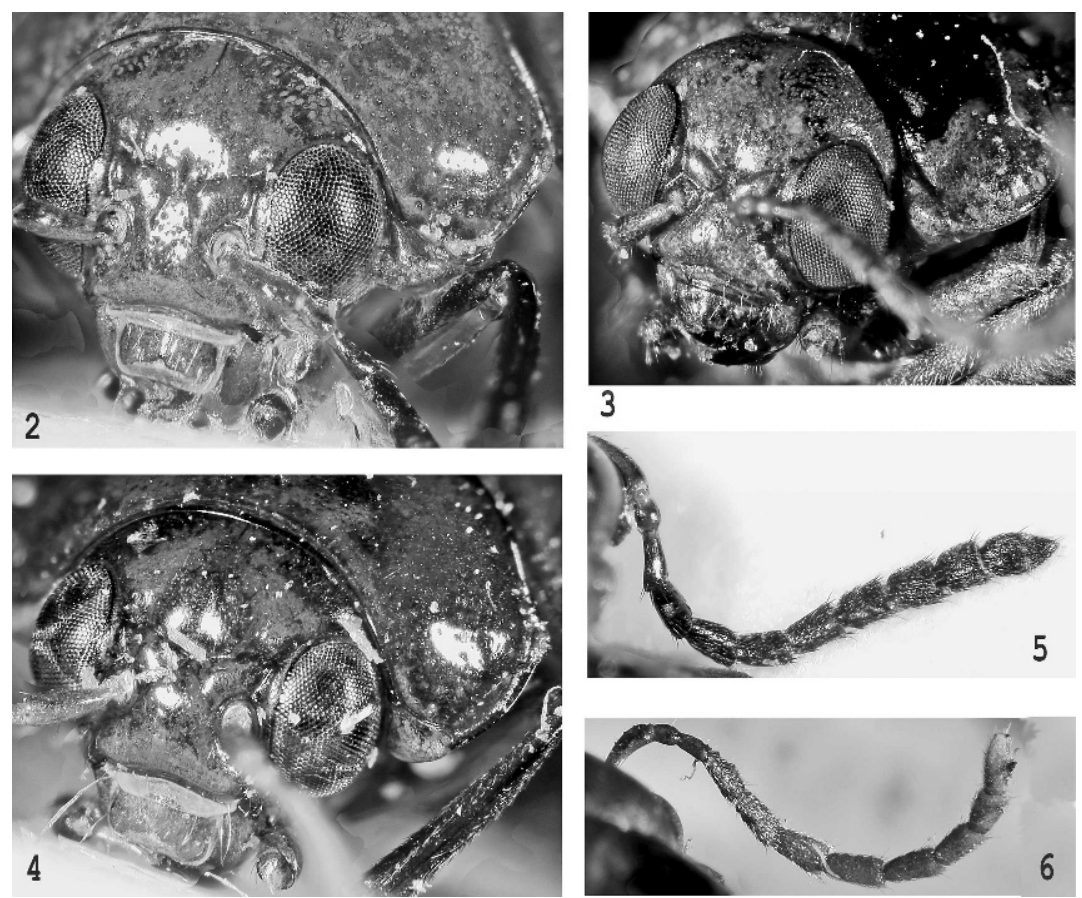

Figs. 2-6. Details of morphology of Acrocrypta species. 2) head of A. mouhoti; 3) head of $A$. nigripennis; 4) head of $A$. mindanaica; 5) antenna of $A$. mouhoti; 6) antenna of A. nigripennis.

combined). Relative width of frontal ridge and length of antennomeres should not be used to separate genera in flea beetles because they vary greatly among species. In fact the frontal ridge of Acrocrypta mouhoti is not wider than in Pseudocrypta and Sebaethiella (Figs. 2, 3, 4). It extends between the antennal calli slightly separating them. Apart from that, there are no significant differences in the heads of beetles of all the three genera. The shape of the antennal calli, frontal and transfrontal ridges, all main sulci, and sutures are essentially the same. All three genera share a globose penultimate maxillary palpomere, a transverse pronotum without impressions, closed procoxal cavities, confused elytral punctures, and lack of a longitudinal furrow along the last visible abdominal tergite. All the tibiae are dorsally convex and ridged. Since the above genera are inseparable by any distinct character, we consider Pseudocrypta and Sebaethiella as synonyms of Acrocrypta.

Material examined:

Acrocrypta mouhoti: 1 female, India, Megalaya State, Wesy Garo Hills, 1,100 m, $25^{\circ} 29^{\prime} 6^{\prime \prime} \mathrm{N} \mathrm{90} 19^{\prime} 5^{\prime \prime} \mathrm{E}, 9-17 . \mathrm{V} .1996$, Jendek (USNM).

Pseudocrypta nigripennis: Paratype 1 female, Philippines, Dapitan, Mindanao,

Baker (USNM); Philippines, Iligan, Mindanao, Baker (USNM).

Sebaethiella mindanaica: Paratypes 3 females, Philippines, Mindanao, 1991, Maramag prov, Portulin, 3. Jan. leg. Bolm (USNM). 


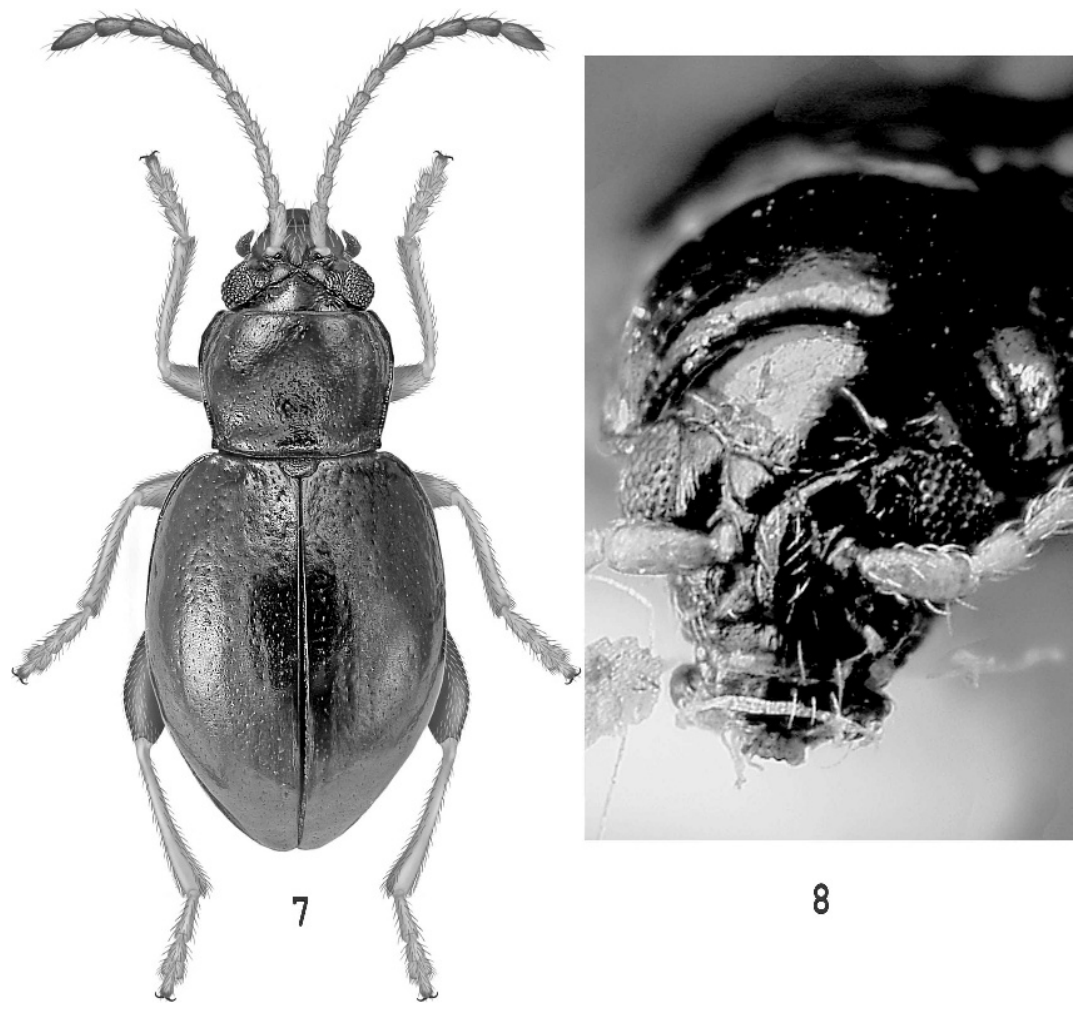

Figs. 7-8. Aphthona metallica. 7) habitus; 8) head.

\section{Aphthona Chevrolat, 1836}

(Figs. 7, 8)

Aphthona Chevrolat, 1836: 391 (type species Altica cyparissiae Koch, 1803, by subsequent designation Maulik, 1926).

Bhutajana Scherer, 1979: 132 (type species Bhutajana metallica Scherer, 1979, by original designation). New synonym

Bhutajana metallica is clearly a wingless Aphthona, as it shares all characters of the head (Fig. 8), antennae, thorax, legs, elytra, and genitalia with Aphthona. It is particularly similar to the Aphthona species from the hammarstroemi group. As with many Aphthona species from the hammarstroemi group, Bhutajana metallica feeds on Rosa sp. in Bhutan. The weak impression on the prothorax and lack of hindwings, on which Scherer (1979) relied heavily in proposing this genus, are shared by several species of Aphthona.

Aphthona gerhardi new name is proposed here for Aphthona nepalensis (Scherer 1989) which is a secondary junior homonym of A. nepalensis Medvedev, 1984.

Material examined:

Aphthona cyparissiae: 2 males, 3 females, Canada, Alberta, Carston, 9.VII.1990, leg. H. Ziolkowski (USNM). 


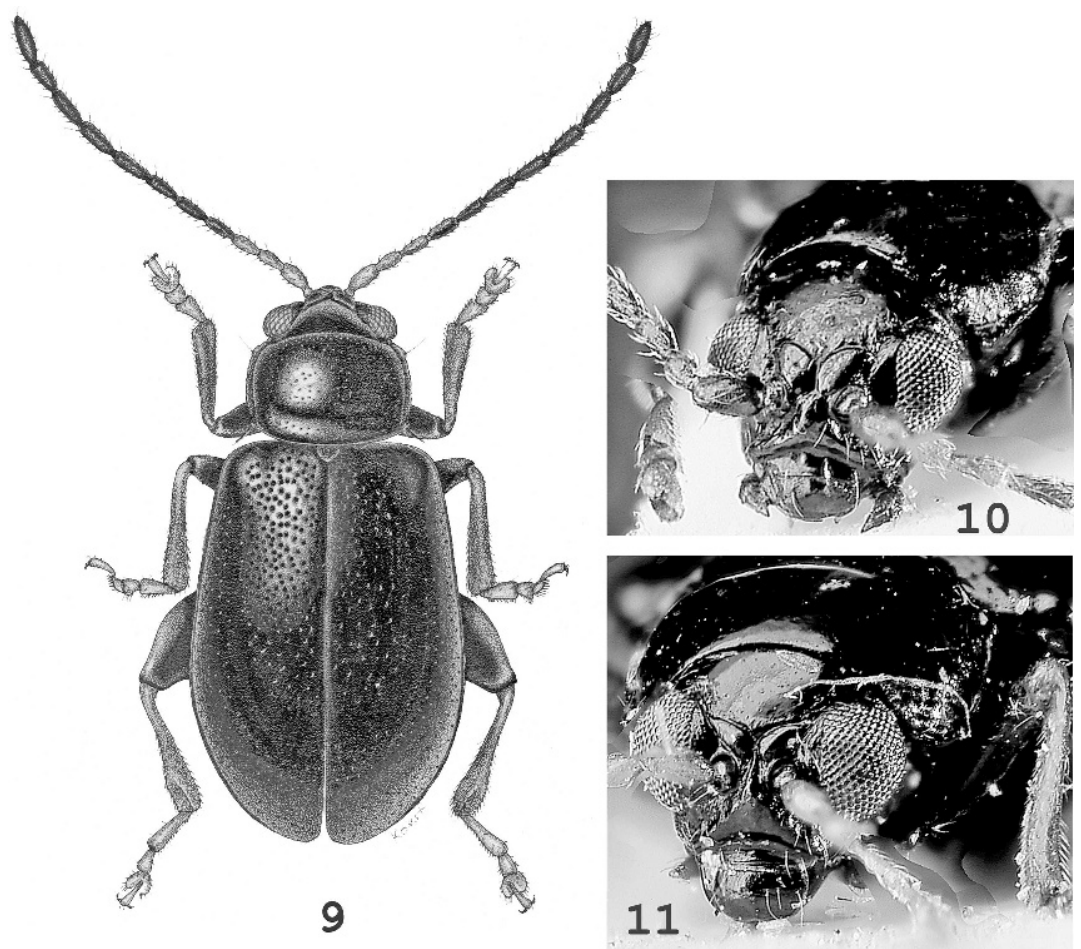

Figs. 9-11. Details of morphology of Aphthonaltica species. 9) A. angustata, habitus; 10) A. angustata head; 11) A. kambaitiensis, head.

Aphthona hammarstroemi: 2 males, 2 females, Kazakhstan, Dzhambul (Aulie Ata), leg. I. Lopatin (USNM); 1 male, Dzhungar Alatau, 11.VIII.1989, leg. A. Tishechkin (USNM); male, Dzhungar Alatau, env. Alma-Ata, leg. V. Palij (USNM); male, Kirgizstan, Issyk Kul, Ton-Fluss (USNM); 12 males, 25 females Russia, Altai, Gorno-Altaisk, 20.VI.1989, leg. S. Saluk (USNM).

Bhutajana metallica: 1 male, 2 females, Bhutan, Wangdi Phodrang, $5 \mathrm{~km}$ E. Nobding, N27 32'38" E90 10'59", 2,863 m (PKDC).

\section{Aphthonaltica Heikertinger, 1924}

(Figs. 9-11)

Aphthonaltica Heikertinger, 1924: 39 (type species Graptodera angustula Baly, 1878 , by original designation).

Burmaltica Scherer, 1969: 122 (type species Haltica kambaitiensis Bryant, 1939, by original designation). New synonym

Scherer (1969) did not compare Burmaltica with Aphthonaltica, although these two genera exhibit remarkable similarity. The structure of the head is similar in all aspects (Figs. 10, 11): general shape of antennal calli well delimited by sulci; frontal ridge unusually short, narrowed between antennae, widening anteriorly to form a curved, anterofrontal ridge; pronotum much wider than long with 
antebasal impression vaguely delimited on either end (Fig. 9); meso- and metatibia convex dorsally while metatibia tends to be flat towards apex. The following combination of other characters useful in generic diagnosis also suggests that they are congeneric: first metatarsomere about as long as rest of tarsi combined, procoxal cavities open, elytral punctures confused, and epipleuron extending beyond $2 / 3$ of elytral length.

Material examined:

Aphthonaltica angustula: 1 male, 1 female, Japan, Honshu, Tokyo pref., Hachiojishi, Minami-Asakawa, Yamashita, 17.V.1992 (USNM); male, female, Japan, Kebe, 17.V.1955 (USNM); male, female, Japan, Takizawa Tage, Ikki-muri, Fukushima, 15.V.1949 (USNM).

Burmaltica kambaitiensis: Paratypes 2 females, N. E. Burma, Kambaiti, 2,000 m, 9/6.1934 Malaise (NHMB, BMNH).

\section{Bikasha Maulik, 1931}

(Figs. 12-18)

Bikasha Maulik, 1931: 256 (type species Bikasha tenuipunctata Maulik, 1931, by original designation).

Aphthonomorpha Chen, 1934b: 357 (type species Crepidodera collaris Baly, 1877, by original designation). New synonym

Manobidia Chen, 1934b: 358 (type species Manobidia antennata Chen, 1934, by original designation). New synonym

Chen (1934b) described both Aphthonomorpha and Manobidia in the same paper. He implied that they differ in the shape of the antennal calli, stating that Manobidia has "prominent frontal tubercles, being separated from each other and sharply delimited behind" (p. 359). As can be seen from the figures (Figs. 13, 14, 15) there is no significant difference between Aphthonomorpha and Manobidia in the shape of the antennal calli. In both cases they are separated by a sulcus from the vertex and from each other, although in Manobidia the sulcus is slightly deeper. In other features they are inseparable from each other and from Bikasha. All of them have elytral punctures regularly or semiregularly arranged (Fig. 12). The lateral edge of the metatibia bears bristles and minute spines. The metabasitarsus in length is subequal to the rest of the tarsomeres combined (Figs. 16, 18).

Material examined:

Aphthonomorpha collaris: 2 males, 2 females, Vietnam, Tam-Dao, $900 \mathrm{~m}$, 15.VI.193, O. Kabakov leg. (USNM).

Bikasha tenuipunctata: Paratypes 2 females, 1) Silhouette, 1908, Seychelles Exp.;

2) Percy Sladen Trust Expedn. B.M. 1927-444 (BMNH).

Manobidia antennata: Holotype 1 male, 1) Tonkin, ??? Tho, HOA-BIN, A. de Cooman; 2) TYPE; 3) Manobidia antennata S. H. Chen det. m. (MNHN).

\section{Chalaenosoma Jacoby, 1893}

(Figs. 19-25)

Chalaenosoma Jacoby,1893: 157 (type species Chalaenosoma metallicum Jacoby, 1893, by monotypy).

Garuda Scherer, 1969: 28 (type species Garuda hindustanica Scherer, 1969, by original designation). New synonym 


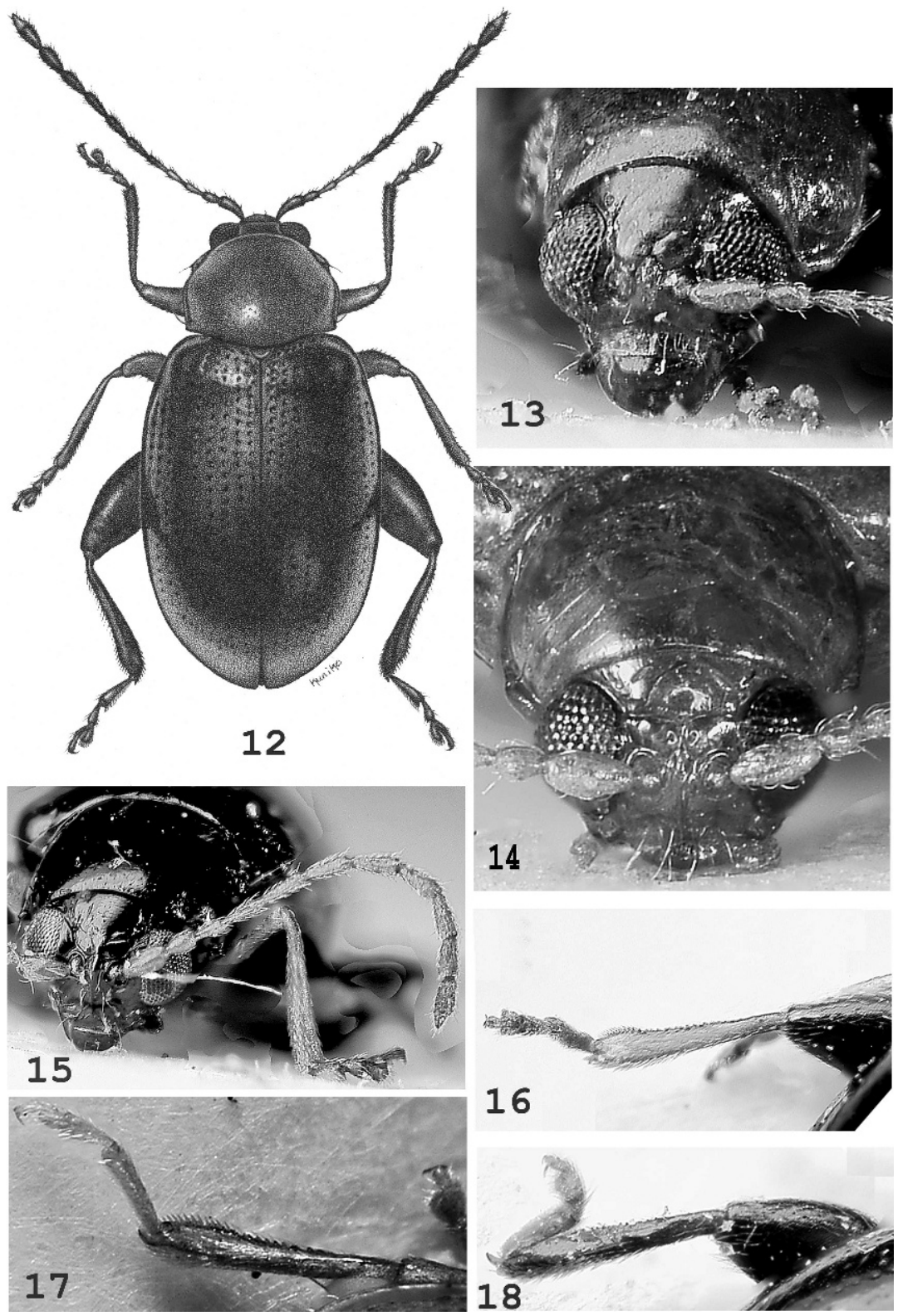

Figs. 12-18. Details of morphology of Bikasha species. 12) B. collaris, habitus; 13) $B$. collaris, head; 14) B. antennata, head; 15) B. tenuipunctata, head; 16) B. tenuipunctata, leg; 17) B. antennata, leg; 18) B. collaris, hind leg. 


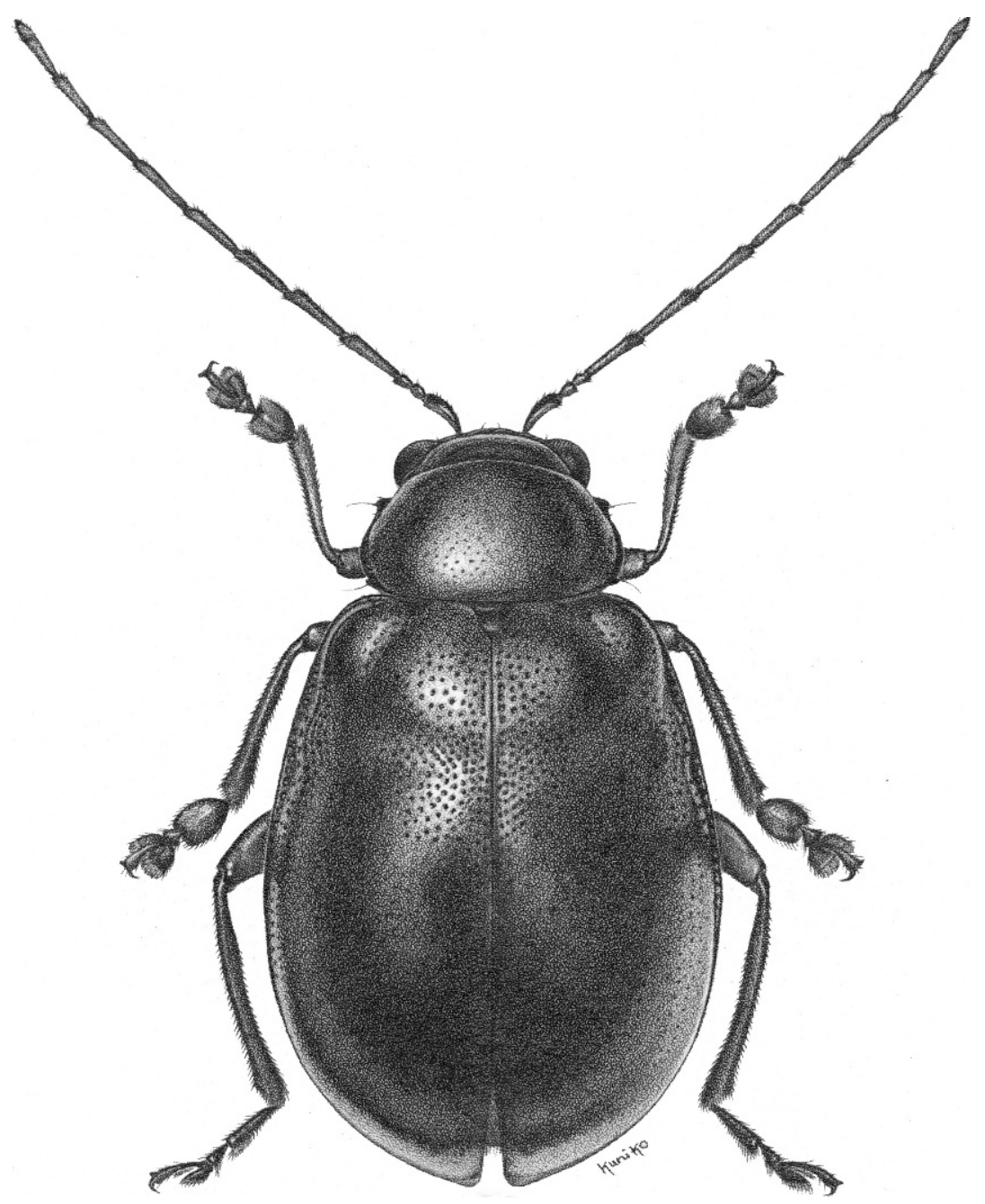

Fig. 19. Chalaenosoma antennatum, habitus.

Garuda is separated from Chalaenosoma by a horn above the wide frontal ridge present only in males (Scherer 1969) (Fig. 25). Width of the frontal ridge is highly variable among species. Even in combination with a feature present only in males, generic level placement of this taxon can not be justified. Garuda is inseparable from Chalaenosoma by all other characters (Figs. 20-25).

Material examined:

Chalaenosoma antennatum Jacoby: 1 female, India, Nilgiris, Coonour, 30.VII.1901, M. Maindron (USNM).

Chalaenosoma spp.: 10 males, 13 females, South India Western Ghats Karnataka, env. Madikeri, Temple Forest, 21.XI.2003 1,138 m, N12 27'31'"E75 41'30”, leg. Konstantinov, Prathapan, Saluk (USNM). 

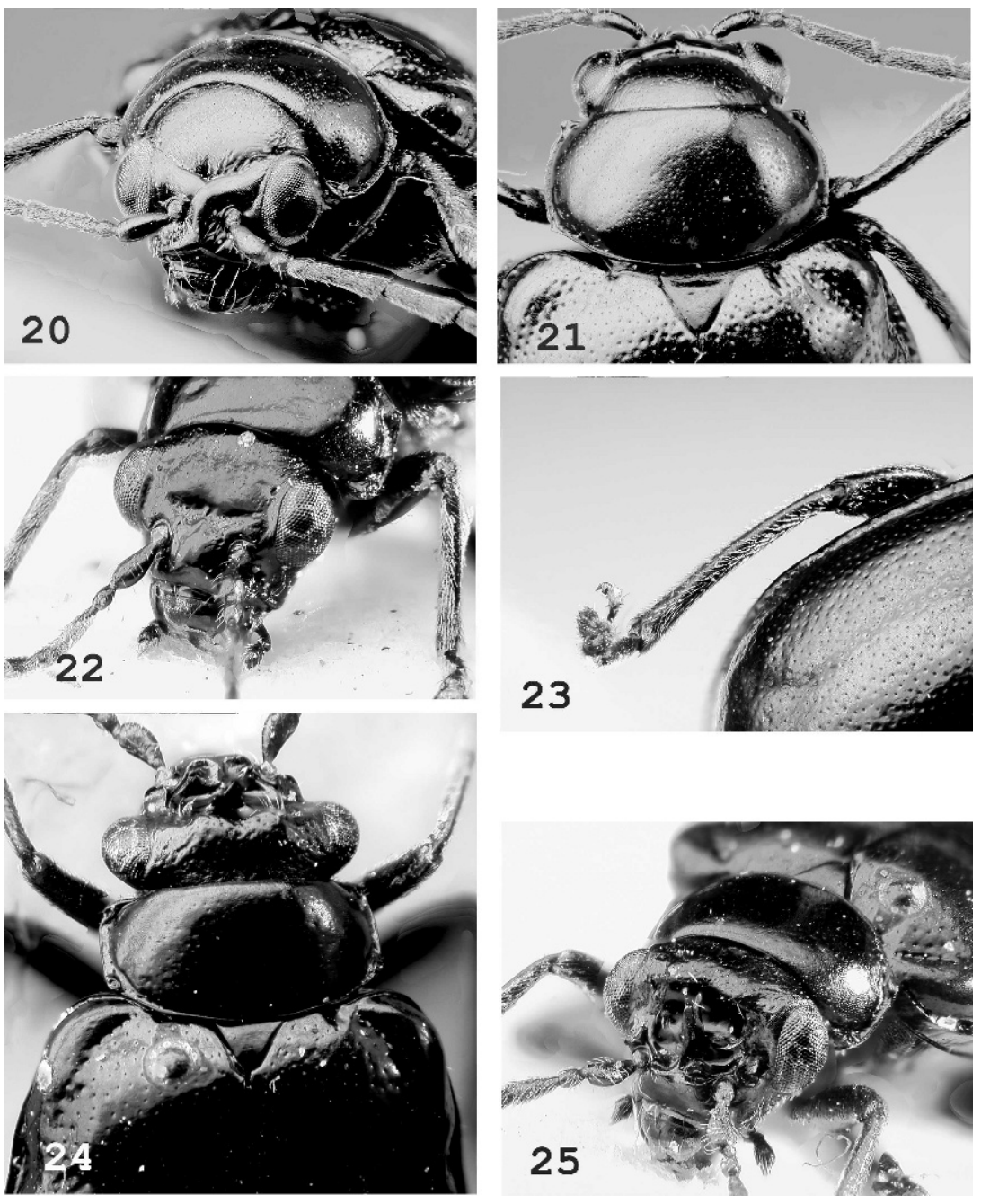

Figs. 20-25. Details of morphology of Chalaenosoma species. 20) C. antennatum, head; 21) C. antennatum, pronotum; 22) C. hindustanicum, female, head; 23) C. antennatum, leg; 24) C. hindustanicum, male, pronotum; 25) $C$. hindustanicum, male, head.

Garuda hindustanica: 2 males, 3 females, Nilgiri Hills, Andrewes (USNM).

\section{Chaloenus Westwood, 1862}

(Figs. 26-30)

Chaloenus Westwood, 1862: 216 (type species Chaloenus latifrons Westwood, 1862 by present designation).

Priostomus Jacoby, 1884: 185 (type species Priostomus unicostatus Jacoby, 1884 by monotypy). New synonym 


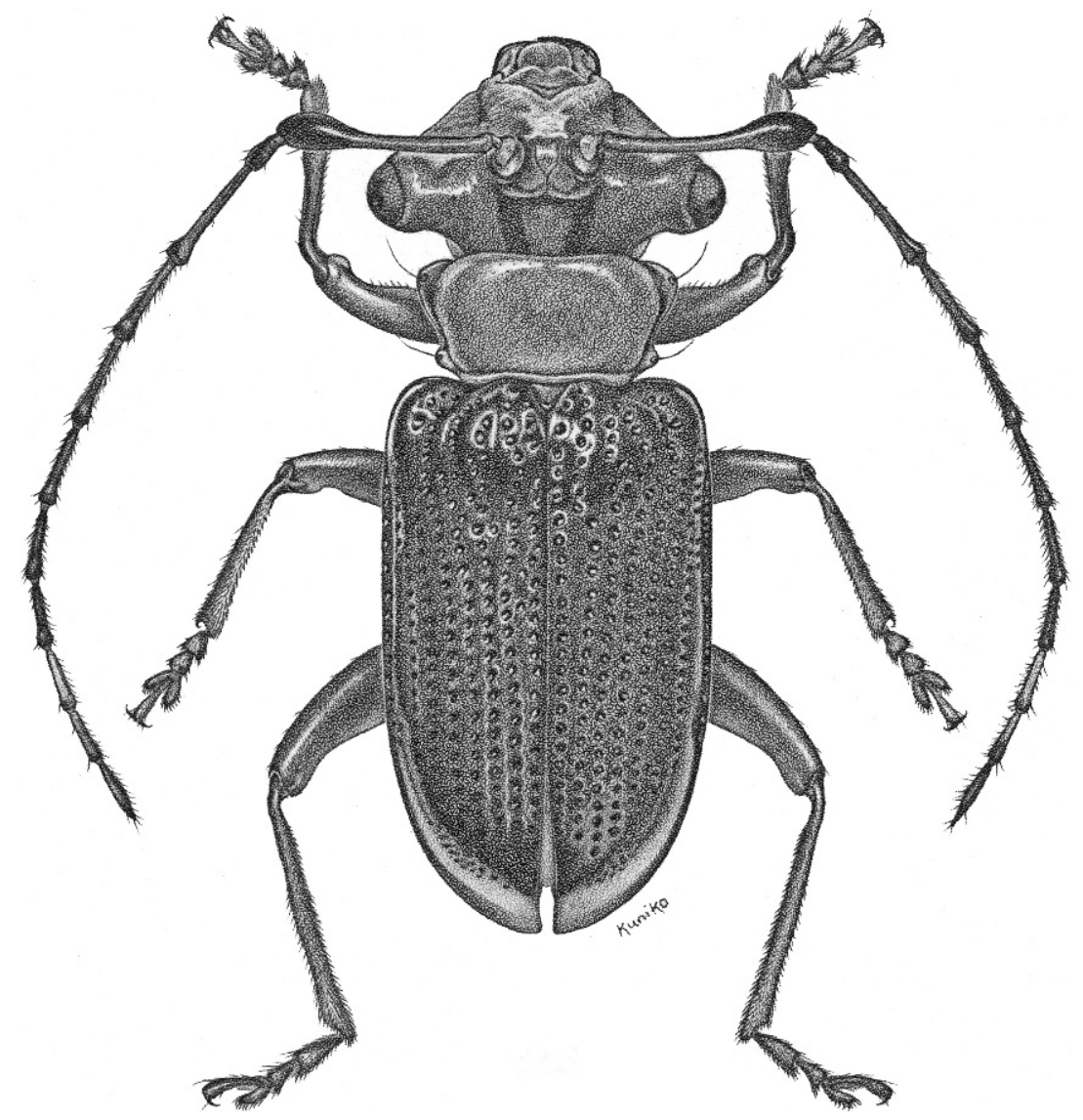

Fig. 26. Chaloenus capitatus, habitus.

We are not aware of any type species designation for Chaloenus. It was originally proposed with two species. The recent so called "revision" of the genus (Medvedev 2004) also failed to designate the type species and also erroneously dated it as 1861 . We here designate Chaloenus latifrons Westwood as the type species of the genus.

Proposing Priostomus, Jacoby (1884) compared it with Febra Clark, however, it is most similar to Chaloenus. The differences between these taxa can be summarized as follows: Priostomus has transverse impressions on the prothorax, while Chaloenus lacks any impression. The elytron of Priostomus is strongly punctate throughout with punctures forming regular striae. Some Chaloenus have a few strong punctures in the post basal area of the elytron which tend to be regular, but the rest of the elytron is weakly punctate. Some other species have the elytra completely covered with punctures. We do not consider these differences important enough to keep these species in two separate genera. Interestingly, Medvedev's concept of Chaloenus includes species with an impression on the 


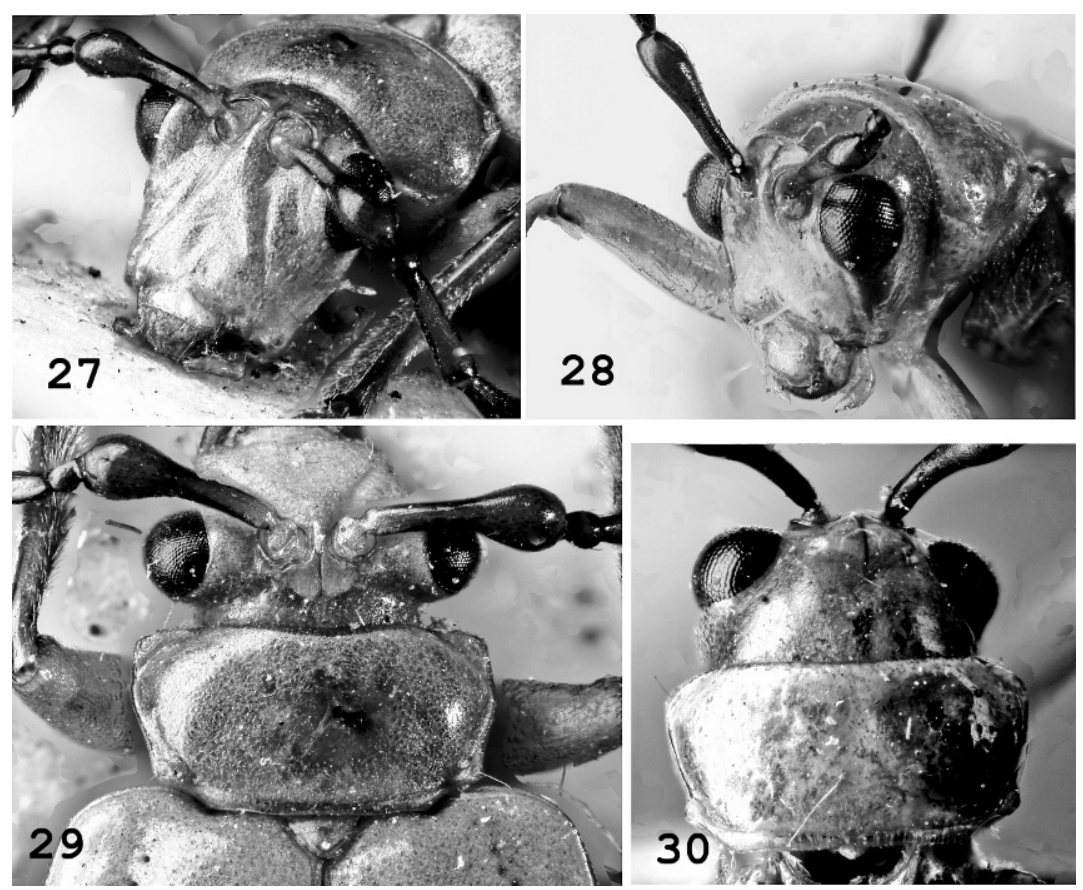

Figs. 27-30. Details of morphology of Chaloenus species. 27) C. capitatus, head; 28) $C$. unicostatus, head; 29) C. capitatus, pronotum; 30) C. unicostatus, pronotum.

pronotum and with the elytra completely covered with punctures (Medvedev 2004). Both Priostomus and Chaloenus have extremely similar unique structure of the head (Figs. 27, 28), with laterally bulging eyes (Figs. 29, 30), antennal calli broadly connected and roughly quadrangular with slightly angulate ends entering interantennal space, frons flat, triangular, long, narrowed between antennal sockets and greatly widening and not forming ridge anteriorly, first antennomere long with characteristic club shape, second antennomere very short. They also share unique structure of elytron (Fig. 26): distinctly explanate margin, prominent humeral callus with distinct post basal depression and vertically oblique epipleuron. In both genera, all tibiae are dorsally convex and the last abdominal tergite lacks a longitudinal groove along middle. The general shape of the body is also the same. Because of the above unique features, we synonymize Priostomus with Chaloenus.

Material examined:

Chaloenus capitatus Jacoby: 1 female, Indonesia, Mentawei, Sipora, Sereinu, VO. 1894, Modigliani; 2) Mentawei, Sipora, Sereinu, V-VI.94, Modigliani; 3) 215; 4) F. Monros Collection; 1959; 5) Chaloenus capitatus Jac. (USNM). Chaloenus furthi Medvedev: 1 male, Palawan, Cleopatra Needle Mt. P., Tanabank Riv. Val. 300 m, 20-22.12.1990 Bolm leg. (USNM).

Priostomus unicostatus: Syntype 1 male, 1) Java; 2) $1^{\text {st }}$ Jacoby coll.; 3) Type 19370 (MCZC). 

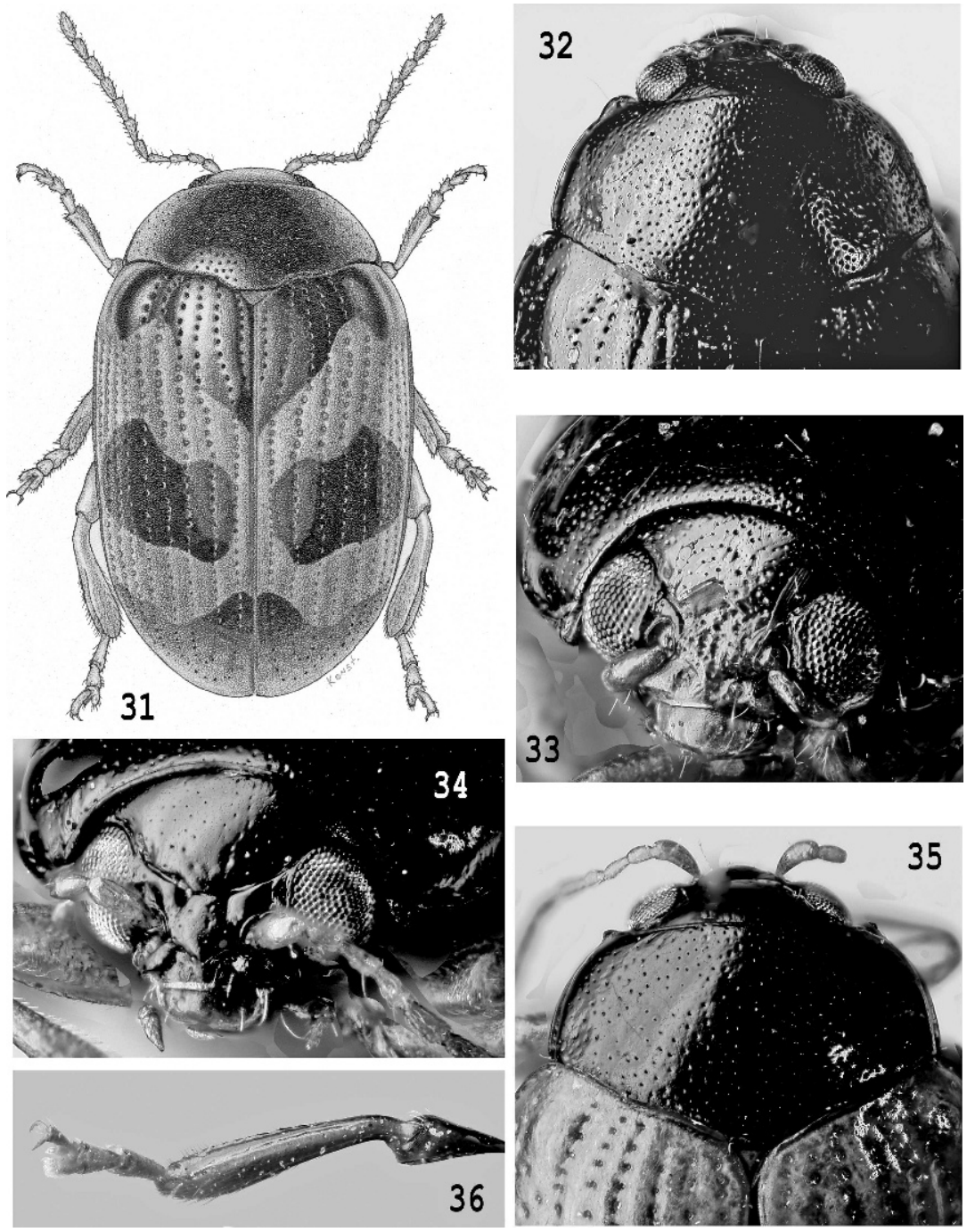

Figs. 31-36. Details of morphology of Clitea species. 31) C. picta, habitus; 32) C. picta, pronotum, 33) C. picta, head; 34) C. citri, head; 35) C. citri, pronotum; 36) C. picta, hind leg.

\section{Clitea Baly, 1877}

(Figs. 31-36)

Clitea Baly, 1877: 287 (type species Clitea picta Baly, 1877, by monotypy).

Throscoryssa Maulik,1928: 161 (type species Throscoryssa citri Maulik, 1928, by original designation). New synonym

Proposing Throscoryssa, Maulik compared it to Kamala Maulik which is very distant from it, based on a variety of features including the head, thorax, legs, 
antennae, and genitalia. Throscoryssa should have been compared to Clitea, which is similar to it morphologically and biologically: both feed on the leaves of Rutaceae as larvae and adults. Throscoryssa and Clitea have the same basic structure of the head, though the antennal calli are quadrangular and larger in $T$. citri (Figs. 33, 34). The combination of the following characters clearly suggests that they are congeneric: widely separated, laterally bulging eyes, narrow orbit, widely separated antennal sockets, antennal calli oblique and widely separated from each other, lacking suprafrontal sulcus, flat and wide frontal ridge forming discontinuous anterofrontal ridge raised on either side and flat in middle; prothorax weakly bisinuate with weak lobe in middle, anterior callosity transverse and wider than long and projecting forward (Figs. 31, 32, 35), scutellum triangular and smooth; elytron with highly regular, distinct punctures and flat lateral sides, epipleuron horizontal anteriorly and gradually narrowing towards posterior end, reaching near apex; all femora sulcate beneath for reception of tibia, all tibiae short, either edge of dorsal side distinctly margined and flat or concave, distally widening, armed with a spine; metafemora dorsoventrally flat; last visible abdominal tergite with longitudinal groove. Because of the above combination of unique characters, Clitea and Throscoryssa are considered synonyms.

Material examined:

Clitea picta: 1 female, Birmania, Bhamo, VI. 1886, coll. Fea (USNM).

Clitea metallica Chen: 1 male, Japan, Okinawa, 1898 (USNM).

Throscoryssa citri: Paratypes 8 females, 4 males, Shillong, Assam, 20.III.1926, C. P. Clausen (USNM).

\section{Halticorcus Lea, 1917}

(Figs. 37-42)

Halticorcus Lea, 1917: 319 (type species Halticorcus platycerii Lea, 1917, by monotypy).

Eucycla Baly, 1876: 439 (type species Eucycla quadripustulata, Baly, 1876, designated by Maulik, 1926). Homonym of Eucycla Bonaparte, 1854 (Aves) .

Eucyclomela Chen, 1934a: 73 (type species Eucyclomela clypealis Chen, by original designation). New synonym

Schenklingia Csiki \& Heikertinger, in Heikertinger \& Csiki, 1940: 516 (replacement name for Eucycla Baly). New synonym

Describing Eucylomela, Chen (1934a) compared it with Chilocoristes Weise and Eucycla Baly. He suggested that it can be separated from the former by the "long first antennal segment and the small and slender maxillary palpi; from the latter, by the deeply concave epipleura and the entire third segment of the tarsi" (page 74). Contrary to Chen's opinion, Schenklingia does have an entire third tarsomere (Fig. 40, 43). The structures of the epipleura also does not provide distinguishing characters. It is concavely oblique in all taxa under consideration and is slightly more so in Eucyclomela (Fig. 42).

All the above genera and Halticorcus share a number of important characters including an apparent hemispherical body shape, and a long first antennomere which is as long as the next three combined. Usually they are colored in shades of yellow or red with black spots. The frontal ridge is flat, anteriorly widened with lateral carinae forming a groove below the eyes for accommodating the antennae. The posterior margin of the pronotum is bisinuate (Figs. 37, 39). The legs are short and the dorsal surfaces of all tibiae are flat or depressed. Eucycomela clypealis 

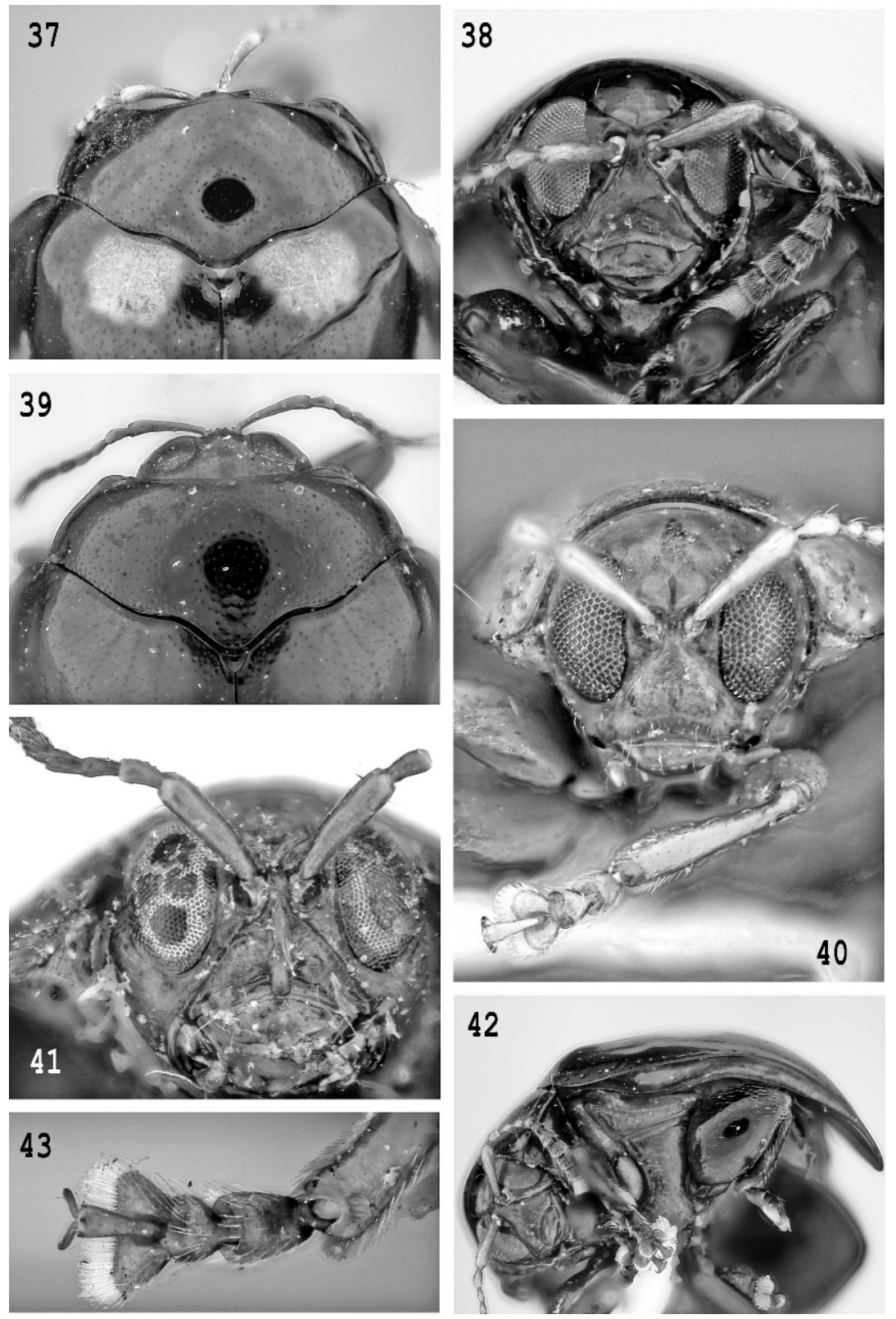

Figs. 37-43. Details of morphology of Halticorcus species. 37) H. platycerii, pronotum; 38) $H$. platycerii, head; 39) $H$. quadripustulatus, pronotum; 40) $H$. esaki, head; 41) $H$. clypealis, head; 42) $H$. platycerii, ventral side of the body; 43) H. clypealis, metatarsus. 
differs from the types of Schenklingia and Halticorcus in having a long projection on the frons (absent in Halticorcus and Schenklingia), which we consider as an aberrant modification. We hence treat all these names as synonyms.

Halticorcus platycerii was reported eating the fern Platycerium grande (Fee.) Kunze (Lea 1917). Schenklingia is also known to feed on ferns in India (Patra and Bera 2007).

Material examined:

Eucyclomela clypealis: Syntype 1 male, 1) Kuching, ap. 09; 2) Kuching J. I. A. Lewis 1910-116 (BMNH).

Eucyclomela clypealis f. inornata: Syntype 1 male, 1) Doherty; 2) Sumatra, Merang; 3) Frey Coll. 1905-100 (BMNH).

Halticorcus platycerii: Syntypes 1 male, 1 female, Stag horn fern. Sydney, N. S. W. W. Froggatt, 15.190; 2) Pres. by Imp. Bur. Ent. Brit Mus. 1922-108 (BMNH). 1 female, Australia, NSW. 15.II.96 T. Hawkeswood (BPBM).

Halticorcus zophos Samuelson: Holotype 1 male, Above Keqlsuql; 2) New Guinea (NE) Mt. Wilhelm 3,000 m, July 4. 1955 (BPBM).

Schenklingia quadripustulata: 1 female, 1) lar Wallace; 2) Baly Coll.; 3) Right hind leg mounted in balsam, S. Maulik 1929; 4) Abdominal contents in vial dissected by G. A. Samuelson, 1966 (BMNH).

Schenklingia esakii Chûjô: 1 male, 1 female, Japan, Ryukyu Isl. Okinawa, 1898 (USNM).

Schenklingia spp.: 3 males, 4 females, Nepal. Terrai, W Narayangadh, small valley, Rapti river 26.IV. $27^{\circ} 42.31^{\prime} \mathrm{N} 84^{\circ} 21.11^{\prime} \mathrm{E}, 2,000$ Konstantinov, Lingafelter, Volkovitsh (USNM); male, Nepal. Pokhara env. Phewa Tal (lake), creek valley 23.IV. $28^{\circ} 17.82^{\prime} \mathrm{N} 83^{\circ} 49.11^{\prime} \mathrm{E}, 2,000$ Konstantinov, Lingafelter, Volkovitsh (USNM).

\section{Laboissierella Chen, 1933}

(Figs. 44-48)

Laboissierella Chen, 1933a: 384 (type species Laboissierella cyanipennis Chen, 1933, by monotypy).

Luperaria Medvedev, 1993b: 373 (type species Luperaria elongata Medvedev, 1993, by monotypy). New synonym

Describing Luperaria, Medvedev (1993b) compared it with Luperomorpha Weise and Trachyaphthona Heikertinger from which it is obviously different by a variety of features. He did not propose any unique characters for Luperaria. Comparison of Luperaria elongata with Laboissierella cyanipennis reveals that they are congeneric. Both Luperaria and Laboissierella have the same structures of the head (Figs. 45, 48), legs and pronotum (Figs. 44, 47), with the basal margin of the latter being separated by a deep furrow from the rest of pronotum. Even male genitalia are similar. The only difference between them is in the degree of the closure of the procoxal cavities. In Laboissierella they are closed, in Luperaria very narrowly open (Fig. 46). The procoxal cavities are known to vary in the degree of their closure in many genera of flea beetles.

Material examined:

Laboissierella cyanipennis: Holotype 1 male, 1) Sou??g, Prabung, Tonkin; 2) type; 3) Museum Paris, Coll. Generale; 4) Laboissierella cyanipennis n. g. n. sp. S. H. Chen det. (MNHN).

Luperaria elongata: Paratype 1 male, 1) China, N. Yunnan, $30 \mathrm{~km} \mathrm{~N}$. of Lijiang, 3,000 m, 3.VII.1990. L. \& M. Bocak ldt. (NHMB). 


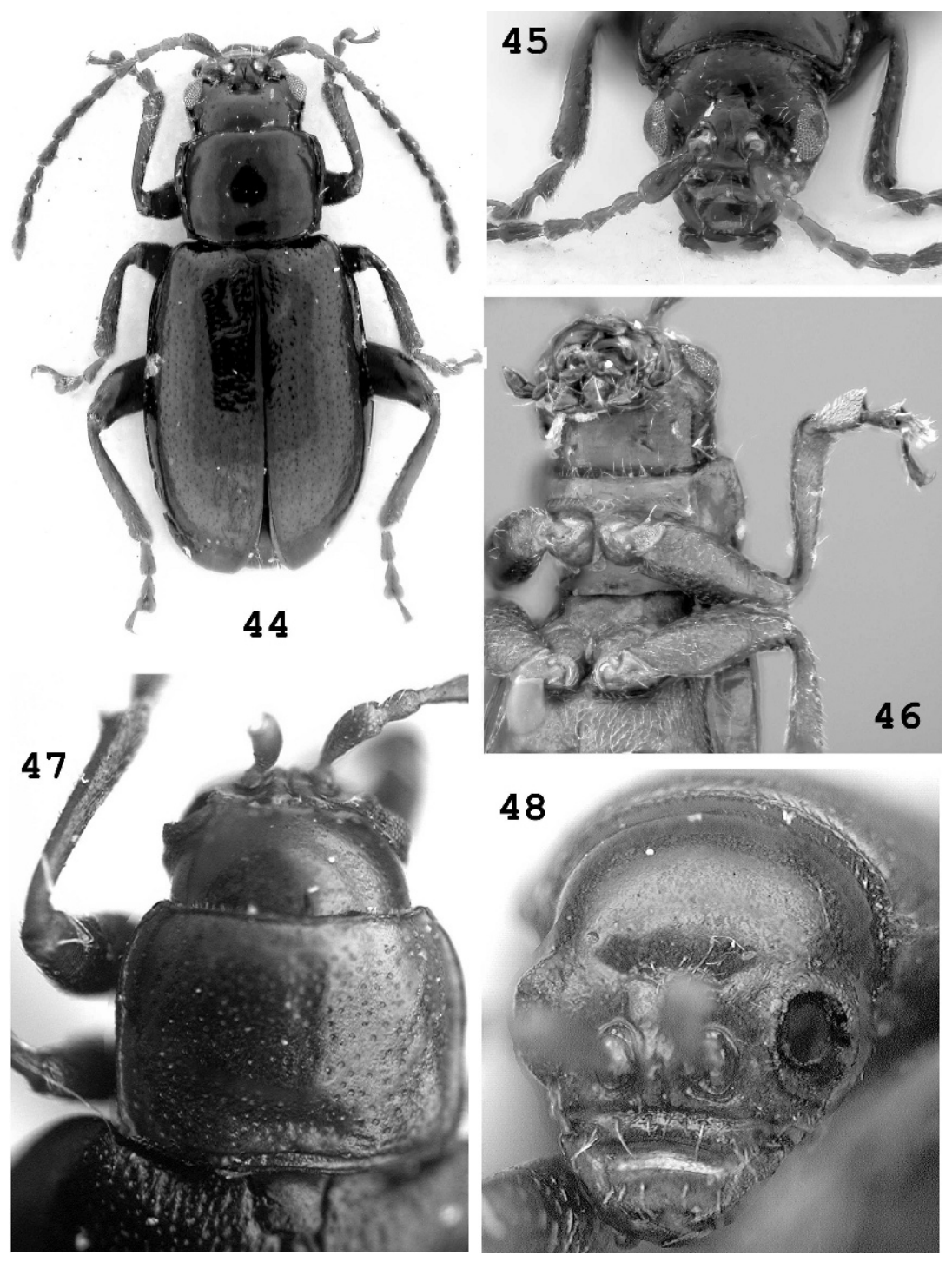

Figs. 44-48. Details of morphology of Laboissierella species. 44) L. elongata, habitus; 45) $L$. elongata, head; 46) $L$. sp., prosternum; 47) $L$. cyanipennis, pronotum; 48) $L$. elongata, head.

\section{Lanka Maulik, 1926}

(Figs. 49-52)

Lanka Maulik, 1926: 304 (type species Lanka brunnea Maulik, 1926, by original designation).

Dentisterna Medvedev, 1993b: 353 (type species Dentisterna bicolor Medvedev, 1993, by original designation). Konstantinov and Vandenberg 1996: 320 (synonymy). 


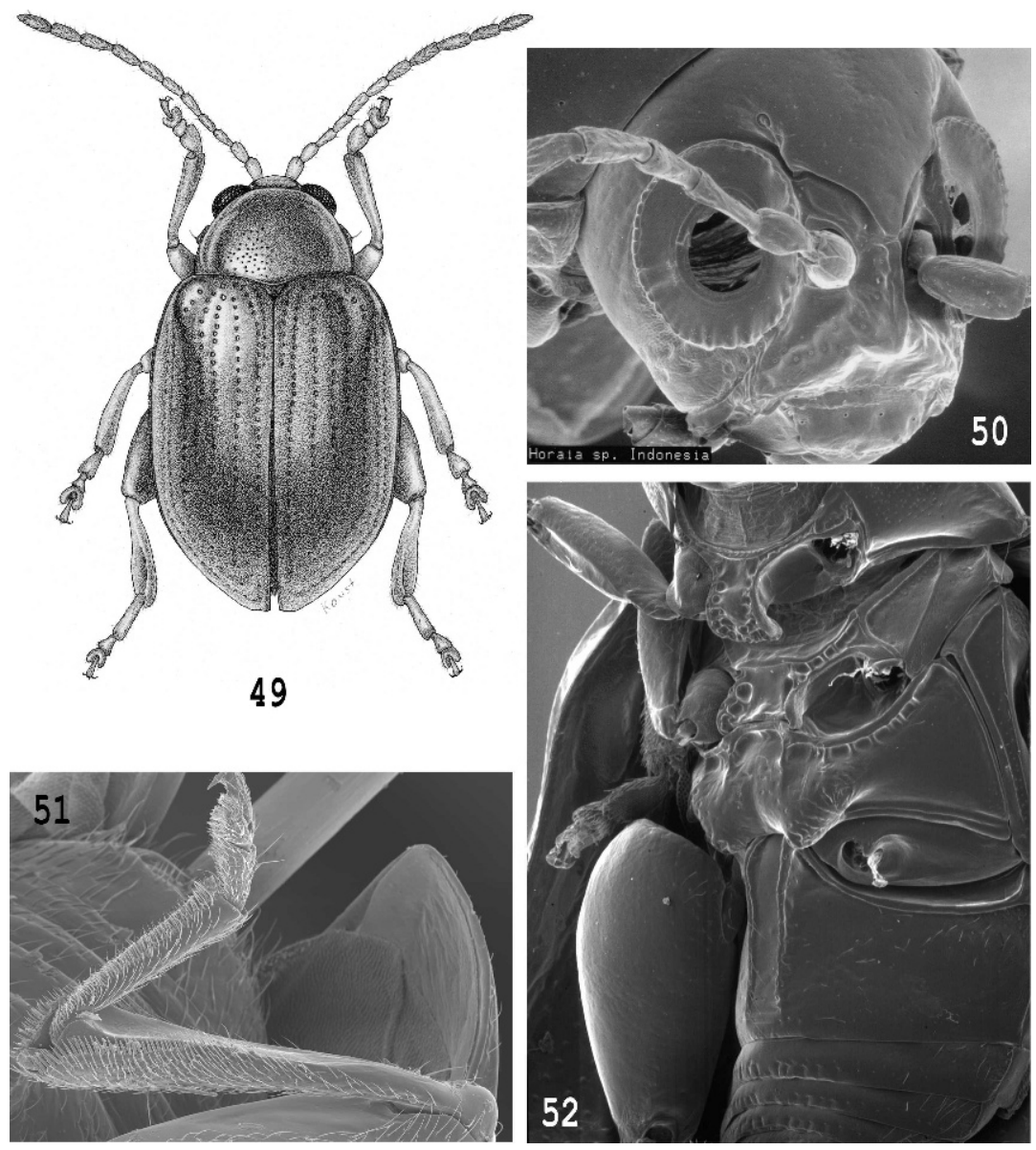

Figs. 49-52. Details of morphology of Lanka species. 49) L. fulva, habitus; 50) $L$. sp. head; 51) $L$. sp., hind leg; 52) $L$. sp., ventral side of the body.

Horaia Chûjô, 1937: 55 (type species Horaia nigra Chûjô, 1937, by original designation). Kimoto and Takizawa 1994: 337 (synonymy).

In their treatment of Japanese leaf beetles, Kimoto and Takizawa (1994) included Horaia species within Lanka, but provided no justification for it. Below we justify this synonymy and provide additional data for the taxa in question.

The name Horaia was first mentioned by Chûjô in 1935 in the key to the genera of flea beetles of the Japanese Empire. The full generic description and the description and designation of the type species were published later in March of 1937. Since the name was proposed after 1931, the correct date should be 1937.

Proposing Horaia, Chûjô (1937) compared it with Lanka, however, it is unclear if he had reliably identified specimens of Lanka or used a description of it. $\mathrm{He}$ used the following characters to distinguish Horaia: "the basal margin of pronotum with a median lobe and bisinuate on either sides of the lobe, the second 
antennal joint distinctly thicker than any one of the following nine joints, the first tarsal joint of posterior legs longer than the two following combined together."

Our comparison of the holotype of Lanka brunnea with a number of Horaia species, including $H$. fulva Chûjô, shows that the characters proposed by Chûjô to separate Horaia from Lanka are inadequate. The basal margin of the pronotum (Fig. 49) in both genera is the same. The second antennomere is slightly thicker than the third and fourth (Fig. 50), but certainly not thicker than $11^{\text {th }}$ in Horaia or Lanka. The first metatarsomere in Horaia is as long as in Lanka (Fig. 51). Horaia and Lanka also share a number of unique features, including antennal calli strongly depressed, separated from each other by a narrow ridge; vertex raised above antennal calli; frontal ridge joining vertex inseparably; orbit narrow, situated much lower than its adjacent border with vertex (Fig. 50); elytral punctures regularly arranged (Fig. 49); subparallel ridges along the middle of the first abdominal sternite (Fig. 52); metatibia apically widening with flat dorsal surface (Fig. 51); and many more. Based on this, we here synonymize Horaia with Lanka.

Dentisterna was synonymized with Horaia some time ago (Konstantinov and Vandenberg 1996) however, Medvedev continued to treat it as valid, describing species. We would like to reiterate that Dentisterna and Horaia are indistinguishable by any character and should be treated as synonyms. Taking into consideration the synonymy of Dentisterna, Horaia and Lanka and the resultant secondary homonymy, we propose Lanka philippina new name for Horaia bicolor (Medvedev 1993) being a junior homonym of Lanka bicolor (Chûjô 1937) and Lanka ogloblini new name for Horaia fulva (Medvedev 1993) being a junior homonym of Lanka fulva (Chûjô 1937).

Material examined:

Lanka brunnea: Holotype 1 male, 1) Type; 2) Ceylon, G, Lewis, 1910-320; 3) Right leg mounted in balsam. S. Maulik, 1929; 4) Lanka brunnea Mlk, Det. S. Maulik, n.g \& n. sp. 1924 (BMNH).

Horaia fulva: 1 male, 1) Rukyu Is. Lehigaki I, XII-20-30-52, C. E. Bohart; 2) Horaia fulva Chûjô J. L. Gressitt det. 196 (USNM).

\section{Lipromela Chen, 1933}

(Figs. 53-55)

Lipromela Chen, 1933c: 144 (type species Lipromela costata Chen, 1933, by monotypy).

Lipraria Medvedev, 1990: 38 (type species Lipraria variipennis Medvedev, 1990, by original designation). New synonym

Describing Lipraria, Medvedev (1990) compared it to Lipromorpha Chûjô and Kimoto and Eudolia Jacoby and suggested that Lipraria differs from both "in the sculpture of prothorax with two transverse furrows" (Medvedev 1990, page 38). However, Lipraria is the most similar to Lipromela. Lipraria and Lipromela are inseparable by any reliable character. Both of them share the following characters, and hence are considered synonyms: antennal calli broadly connected, anterior ends entering in to interantennal space; eyes moderately small, lateral; frontal ridge narrow in interantennal space, widening anteriorly; anterofrontal ridge triangular, sharply raised laterally; vertex smooth, orbital sulcus distinct (Fig. 54); pronotum distinctly narrowed posteriorly with well developed transverse impressions proximally, distal impression varying from well developed to barely noticeable; scutellum moderately large and triangular; elytron distinctly 

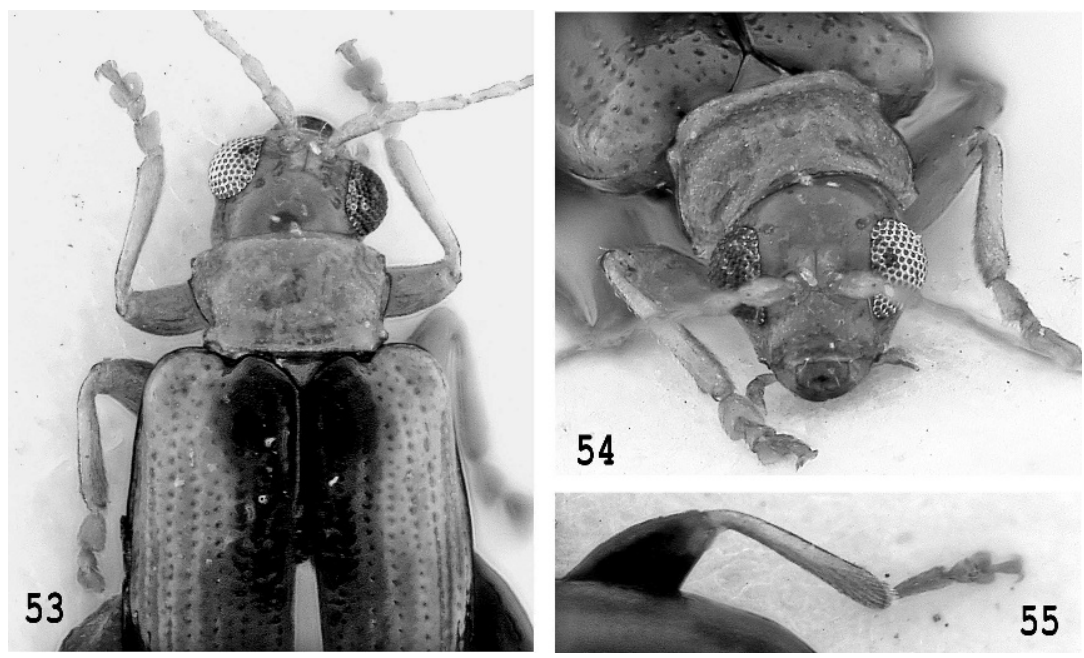

Figs. 53-55. Lipromela variipennis. 53) dorsal side of the body; 54) head; 55) hind leg.

broader than pronotum at base, humeral callus well developed with mesal depression as well as posterior depression, punctures arranged in striae with interspaces convex, forming raised ridges (Fig. 53); elytral margin characteristically broad; epipleuron broad, subvertical, narrowly reaching near apex; all the tibiae dorsally convex, slender (Fig. 55).

Material examined:

Lipromela costata: Holotype 1 female, 1) Museum Paris, Japon, Nippon Moyen, env. de Tokio, J. Harmand 1906; 2) type; 3) Lipromela costata n. g. n. sp. S. H. Chen det. (MNHN).

Lipraria variipennis: Holotype 1 male, 1) Holotypus; 2) Nepal -Expeditionen, Jochen Martens; 3) 406 Sankhua Sabha Distr, betw. Pahakhola and Karmarang, 1,800-1,500 m, cultural land, bushes, 4 June, 88, J. Martens \& W. Schawaller leg.; 4) Lipraria variipennis m. L. N. Medvedev det. 1989 (SMNS).

\section{Liprus Motschulsky, 1860}

(Figs. 56-58)

Liprus Motschulsky, 1860: 26 (type species Liprus punctatostriatus Motschulsky 1860 , by monotypy).

Asiorella Medvedev, 1990: 31 (type species Asiorella caraboides Medvedev 1990, by original designation). New synonym

Describing Asiorella, Medvedev (1990) briefly compared it with Crepidoderoides Chûjô, which was only known to him by a description. He also mentioned a few structures that he considered unique for Asiorella. They are: "frontal tubercles, position of setiferous pore on prothorax, and unusual basal furrow"(Medvedev 1990). Asiorella has an unusually shaped head with a very short facial part (below the antennal sockets), long antennal calli, swollen area around the eye, and extremely short frontal ridge (Fig. 57). Also the orbital groove is very deep and continues on the posterior part of the eye. The second 


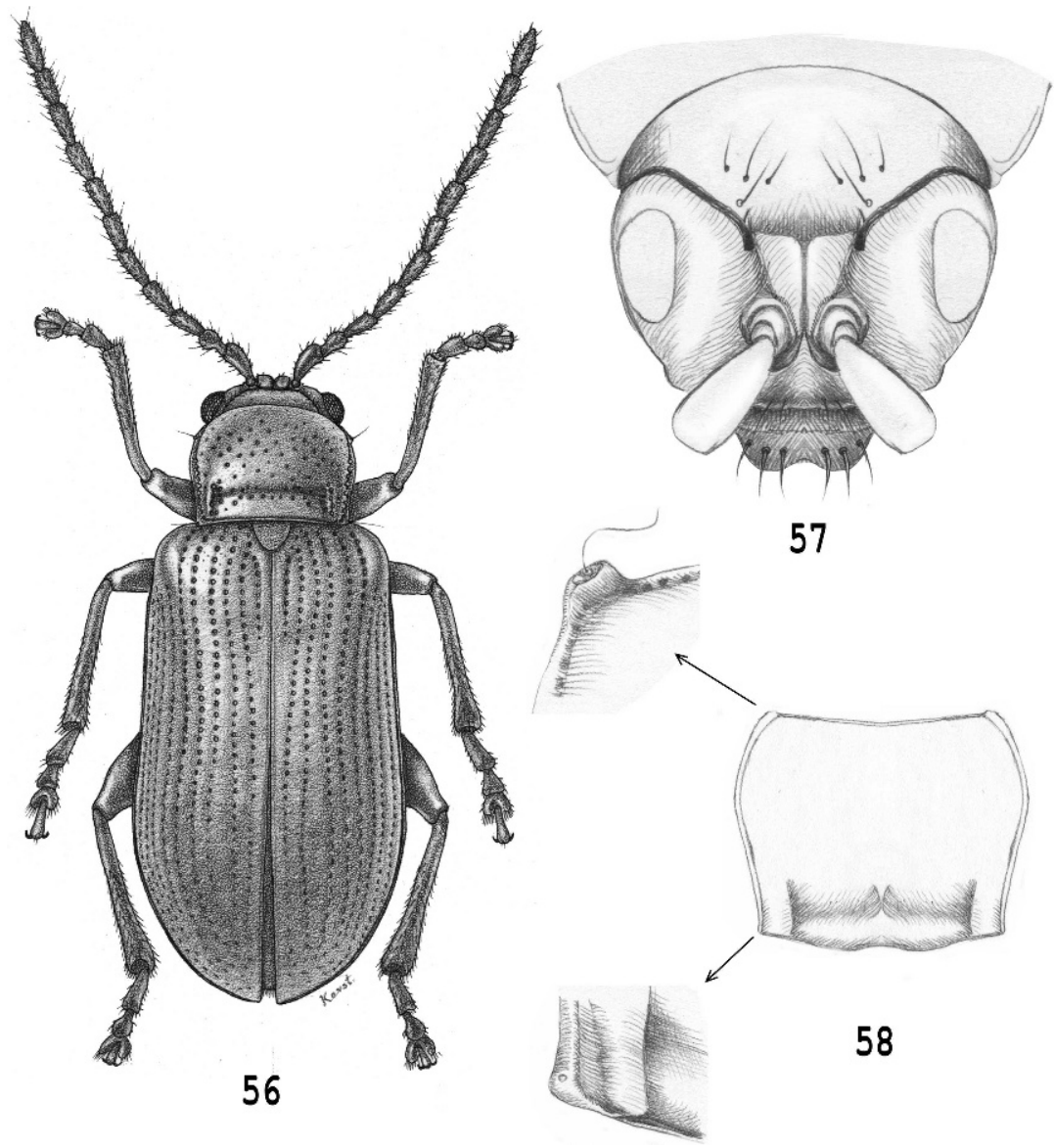

Figs. 56-58. Details of morphology of Liprus species. 56) L. nuchalis, habitus; 57) $L$. punctatostriatus, head; 58) L. punctatostriatus, pronotum.

antennomere of Asiorella is much shorter than the third. The pronotum of Asiorella bears a very simple anterolateral callosity with a setiferous pore in the middle, and in the middle of the antebasal transverse impression there is a well developed longitudinal ridge across the impression (Fig. 58). However, since all these features are easily found in Liprus, we consider Asiorella to be a synonym of Liprus.

Material examined:

Asiorella caraboides: Holotype 1 male, 1) Holotypus; 2) Nepal-Expeditionen Jochen Martens; 3) 404 Sankhua Sabha Distr., above Pahakhola, 2,6002,800 m, Quercus semicarpifolia Rhododendron, 31 May to 3 June 88, Martens \& Schawaller; 4) Asiorella caraboides m. L. N. Medvedev det. 1989; 5) Liprus caraboides (Medvedev) det. A. Konstantinov 2000 (SMNS) Liprus punctatostriatus: 1 male, Russia, Far East, Sideni (USNM). 
Liprus nuchalis Gressitt \& Kimoto: Holotype 1 male, 1) Fukien, S. China, Shaowu: Tachulan, 1,000 m. T. Maa; 2) May 6. 1943; 3) Holotypus male Liprus nuchalis Gressitt \& Kimoto; 4) Liprus HOLO male, sp. nov. nuchalis G \& K det. S. Kimoto; 5) 3323. (BPBM). Paratype 1 female. Labels: 1) Fukien, S. China, Shaowu: Tachfung, Jun 1-3, 1943, T. Maa; 2) Allotype female Liprus nuchalis J. L. Gressitt; 3) Liprus nuchalis female Gressitt \& Kimoto, det. 1942; 4) Liprus sp. nov. det. S. Kimoto. (BPBM).

\section{Luperomorpha Weise, 1887}

(Figs. 59-63)

Luperomorpha Weise, 1887: 202 (type species Luperomorpha trivialis Weise, 1887 [= Phyllotreta funesta Baly, 1874], by monotypy).

Docemasia Jacoby, 1899: 283 (type species Docemasia coerulea Jacoby, 1899). New synonym

Describing Docemasia, Jacoby compared it with Longitarsus Latreille and Cerotrus Jacoby. Both genera are obviously different from Docemasia by a number of features. The type species of Docemasia can easily be identified as a Luperomorpha as it has all the salient features of the genus, like antennal calli merging posteriorly with the vertex (Figs. 59, 61), short second and third antennomeres (Figs. 60, 62), setae on the apex of the elytron, and structure of the metatibiae (Fig. 63).

Material examined:

Docemasia coerulea: Syntype 1 female, 1) Dohrn, Sumatra, Soekaranda; 2) Jacoby Coll. 1909-28a (BMNH).

Luperomorpha funesta: 1 male, Wladivostok, Ost-Asien, Hermann Fleish. (USNM).

Luperomorpha suturalis Chen: 1 female, Russia, Transbaikalia, pl. Dzhida, 20.VII.1928, Th. Lukjanovitsh (ZISP).

\section{Micraphthona Jacoby, 1900}

(Figs. 64-70)

Micraphthona Jacoby, 1900: 125 (type species Micraphthona nigrita Jacoby, 1900 by monotypy).

Ceylonaltica Doeberl, 1996: 110 (type species Ceylonaltica saueri Doeberl, 1997 by original designation). New synonym

Mesopa Jacoby, 1903: 112 (type species Mesopa fulvipes Jacoby, 1903 by monotypy). New synonym

Jacoby (1903) compared Mesopa with Micraphthona and proposed the following characters to separate it: antennae "much more robust, the joints shorter and thickened, the anterior tibiae without spine and the posterior femora less strongly incrassate" (page 113). These characters are known to vary greatly among species of the same genus and, therefore, cannot be used to separate Mesopa from Micraphthona.

Describing Ceylonaltica, Doeberl compared it to Mesopa and mentioned that it can be separated by unnamed characters of the head and pronotum. He also compared it to Chalaenosoma and Garuda and proposed the following features: antennal calli poorly separated from vertex (well separated in Chalaenosoma), orbital line poorly developed (well developed in Chalaenosoma); pronotum with a fine anterior margin (no margin in Chalaenosoma); no transverse impression on 

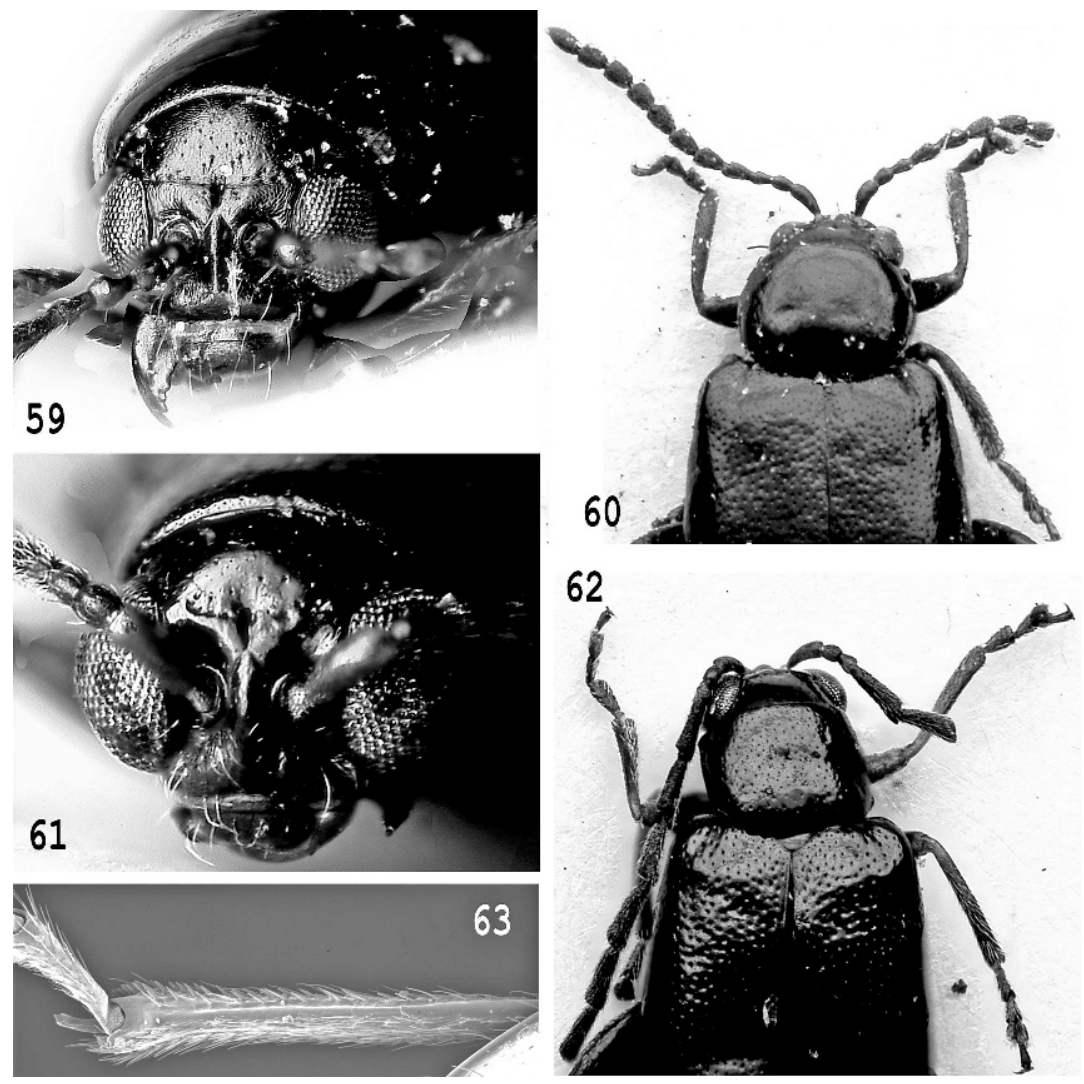

Figs. 59-63. Details of morphology of Luperomorpha species. 59) L. funesta, head; 60) $L$. funesta, pronotum; 61) L. coerulea, head; 62) L. coerulea, pronotum; 63) $L$. funesta, metatibia.

pronotum (fine impression in Chalaenosoma); and proportions of the second antennomere (Doeberl 1996).

Mesopa, Micraphthona, and Ceylonaltica have the same structure of the head (Figs. 65, 68, 70). They have closed procoxal cavities and narrow intercoxal prosternal process. All of them have the same kind of legs and lack a metatibial spine. Some variation is observed in the extent of development of depressions on the prothorax, which we consider as a variable character (Figs. 66, 67, 69). All of them are metallic, medium sized flea beetles with confused or semiregular elytral punctation. General structure of the male and female genitalia is similar across the group (spermatheca lacks a distinct duct, pump curved and not differentiated into horizontal and vertical portions; vaginal palpus fused in the middle with anteriorly directed branches).

Material examined:

Ceylonaltica saueri: Paratype 1 female, Sri Lanka, Kaputale, $06^{\circ} 47^{\prime} \mathrm{N} 80^{\circ} 54^{\prime} \mathrm{E}$, 24-28.IV.1994, leg. R. Sauer (USNM).

Mesopa fulvipes: Syntype 1 female, Nilgiri Hills (BMNH). 

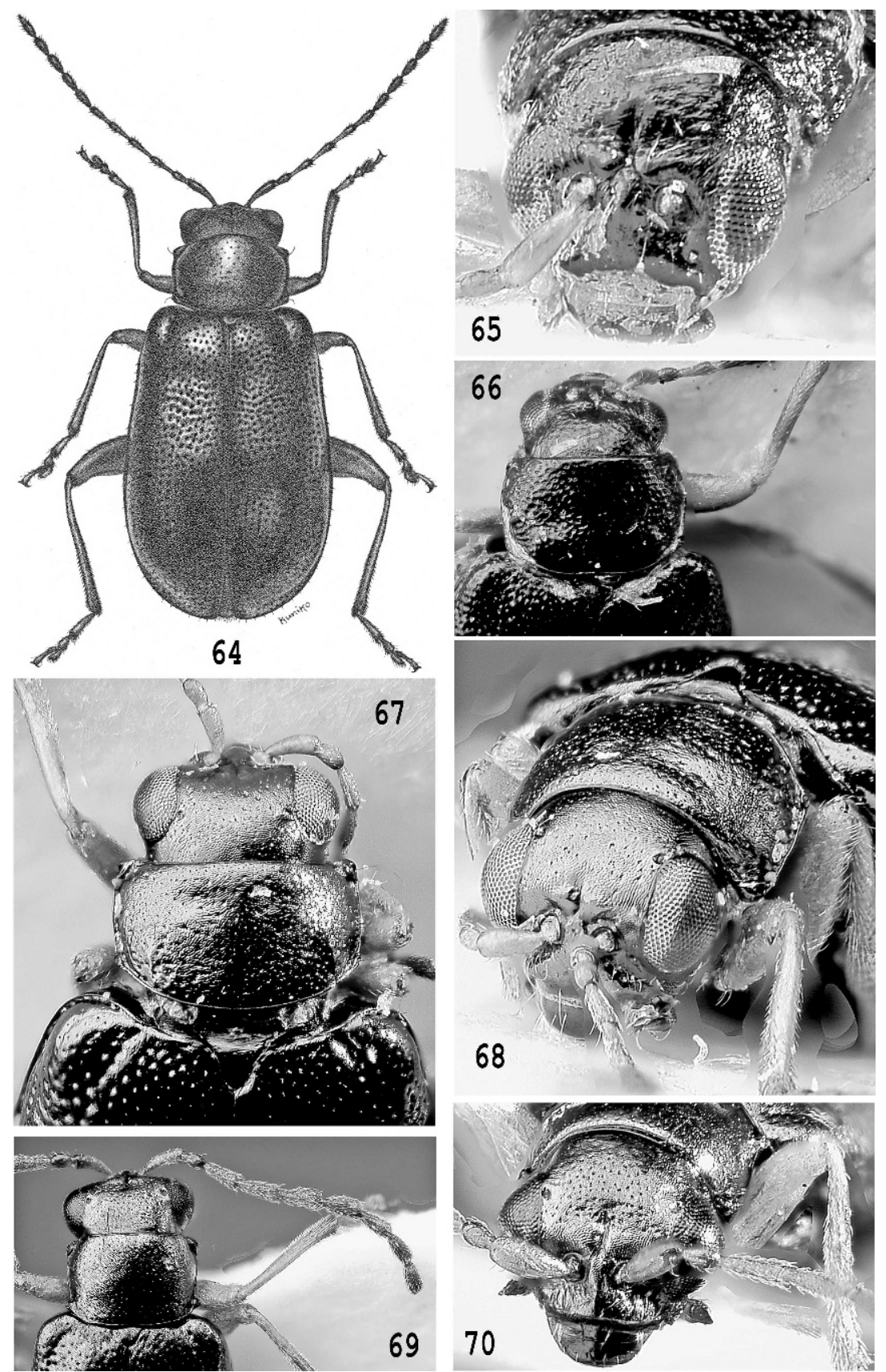

Figs. 64-70. Details of morphology of Micraphthona species. 64) M. fulvipes, habitus; 65) M. nigrita, head; 66) M. nigrita, pronotum; 67) M. saueri, pronotum; 68) M. saueri, head; 69) M. fulvipes, pronotum; 70) M. fulvipes, head. 

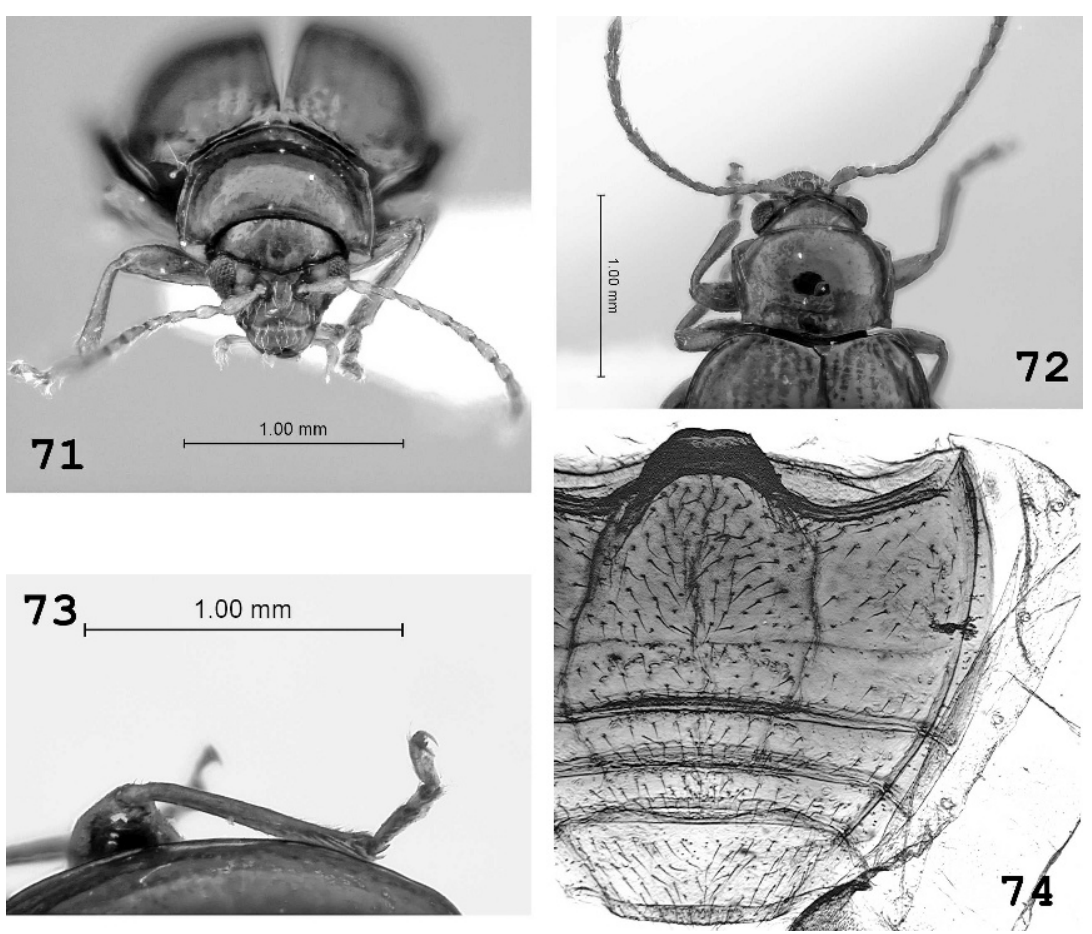

Figs. 71-74. Microcrepis polita. 71) head; 72) pronotum; 73) metatibia; 74) abdominal ventrites.

Micraphthona nigrita: Syntype 1 female, Khasia Hills (BMNH).

\section{Microcrepis Chen, 1933}

(Figs. 71-74)

Microcrepis Chen, 1933b: 449 (type species Microcrepis polita Chen, 1933, by monotypy).

Martensomela Medvedev, 1984: 61 (type species Martensomela aptera Medvedev 1984, by original designation). New synonym

Nepalicrepis Scherer, 1969: 119 (type species Nepalicrepis darjeelingensis Scherer, 1969 , by original designation). New synonym

Proposing Nepalicrepis, Scherer (1969) compared it to Microcrepis, but the comparison was made based on incorrectly identified specimens or original description. The study of the holotype of Microcrepis polita leaves no doubt that it is not only congeneric with Nepalicrepis, but also conspecific with Nepalicrepis darjeelingensis. Therefore, Nepalicrepis darjeelingensis Scherer is a new synonym of Microcrepis polita Chen. That leaves Microcrepis nigra Scherer without generic placement. Our study revealed no significant differences with Microcrepis sensu Scherer and Manobia Jacoby, so we are transferring Microcrepis nigra to Manobia [Manobia nigra (Scherer 1969) new combination]. 
When describing Martensomela, Medvedev (1984) compared it with genera which are obviously not closely related (e.g., Kamala Maulik, Podagricomela Heikertinger, and Panilurus Jacoby); so, the distinguishing characters that he provides cannot be used to separate it from Nepalicrepis and Microcrepis. Here we synonymize Martensomela with Microcrepis based on the following characters: all the head features including general proportions, sulci, and antennal calli are generally the same for both genera (Fig. 71); visible abdominal sternites 1 and 2 are fused together (Fig. 74) (apart from Chaetocnema Stephens, which is obviously different from taxa under consideration, this feature is known only in Microcrepis); the apical abdominal tergite has the same pattern of sclerotization; the metatibiae are extremely similar; and the pronotum of Martensomela aptera has traces of an antebasal transverse impression laterally (Fig. 72). Therefore, most of the structures of these genera demonstrate remarkable similarity. Unfortunately, female genitalia of the holotype of Martensomela aptera cannot be examined since they were lost by Medvedev. The only unusual feature of Martensomela aptera are the abnormally protruding anterior corners of anterolateral callosity; however, these corners are protruding to some degree in all species of Nepalicrepis. Also the pronotum of Martensomela aptera lacks a transverse impression which is well developed in Microcrepis polita. However, Microcrepis besucheti (Scherer) has a poorly developed impression only visible because of the row of large punctures and Microcrepis loebli (Scherer) is dimorphic with respect to it.

Material examined:

Microcrepis polita: Holotype 1 female, 1) Sikkim, Regenzeit, H. Fruhstorfer; 2) Museum Paris, Coll. H. Clavareau; 3) type; 4) Microcrepis politus n. g. n. sp. S. H. Chen det. (MNHN).

Martensomela aptera: Holotype 1 female, 1)Thodung/Those, 3,200 m 39.IV.1973; 2) Holotypus; 3) Holotypus; 4) Martensomela aptera m. L. N. Medvedev det. 1983; 5) Senckenberg Museum, Frankfurt/Main (SMFD).

Nepalicrepis darjeelingensis: 1 female, 1) Singmari-Bhara-patea Bung 10.V.1975;

2) Distr. Darjeeling India, W. Wittmer; 3) Nepalicrepis darjeelingensis Scherer det. Scherer, 1976. (NHMB).

Nepalicrepis himalayensis Doeberl: Holotype 1 male, 1) E. Nepal Kosi, Val. Induwa Kola, 2,800 m, 15.IV.84, Löbl-Smetana; 2) Holotypus Nepalicrepis himalayensis Doeberl, 1990 (NHMG). Paratype 1 female, same label as holotype.

Nepalicrepis schereri Doeberl: Holotype 1 male, 1) Nepal Parbat Distr., Punhill at Ghoropani Pass 3,050-3,100 m, 8.X.83, Smetana \& Löbl; 2) Holotypus Nepalicrepis schereri Doeberl, 1990 (NHMG).

\section{Orthaltica Crotch, 1873}

(Figs. 75-80)

Orthaltica Crotch, 1873: 69 (type species Crioceris copalina Fabricius 1801, by subsequent designation of Scherer, 1974).

Livolia Jacoby, 1903: 15 (type species Livolia sulcicollis Jacoby 1903, by subsequent designation of Scherer, 1974). Scherer 1974: 66 (synonymy).

Epithrella Medvedev, 1993a: 17 (Type species Epithrella philippina Medvedev, 1993, by original designation). New synonym

Livoliella Medvedev, 1997: 100 (type species Livoliella luzonica Medvedev 1997, by original designation). New synonym 

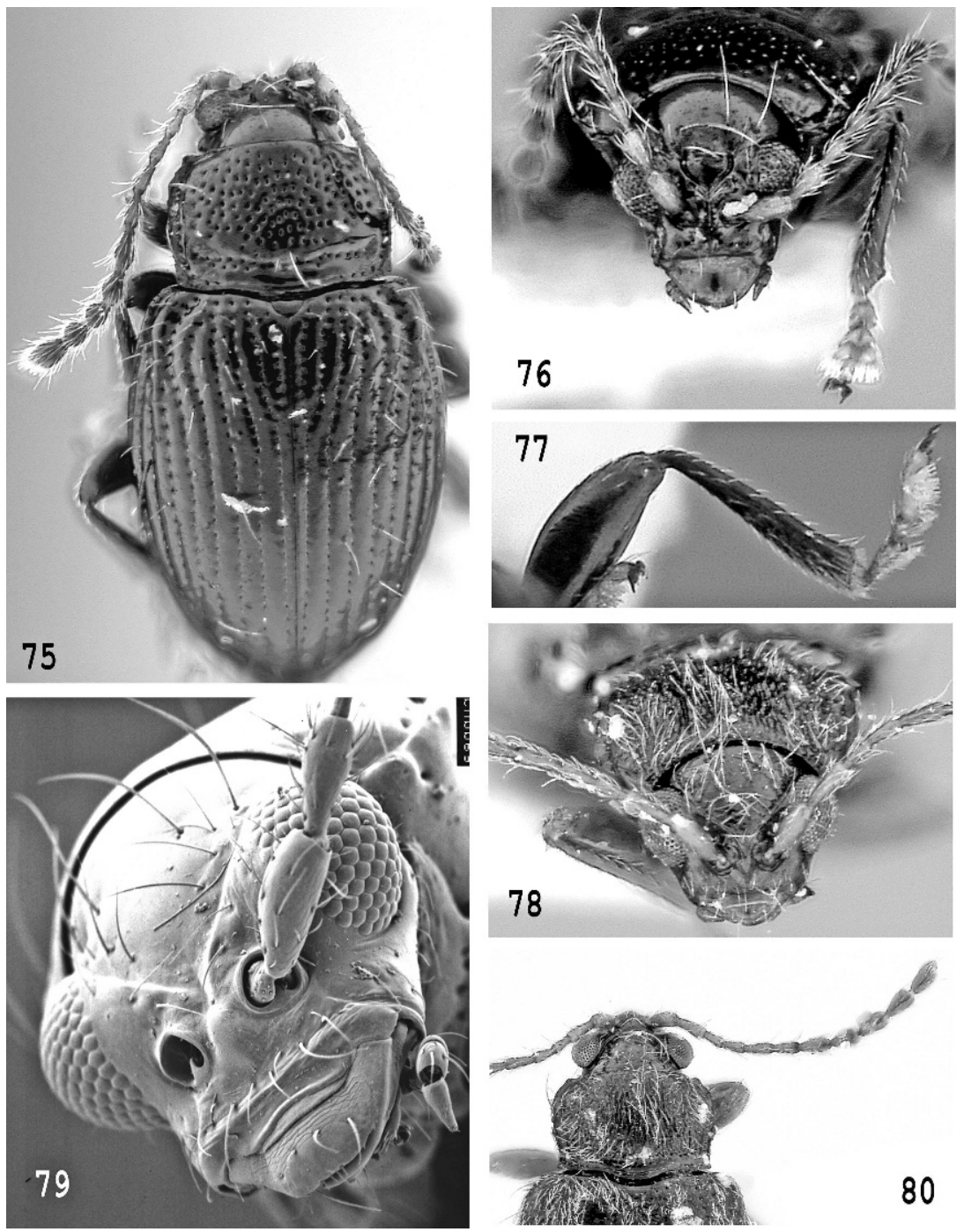

Figs. 75-80. Details of morphology of Orthaltica species. 75) O. borneoensis, habitus; 76) $O$. borneoensis, head; 77) $O$. borneoensis, metatibia; 78) $O$. philippina, head; 79) $O$. philippina, pronotum; 80) O. copalina, head.

Describing Epithrella, Medvedev compared it with Epitrix Foudras and Livolia Jacoby. Epitrix is obviously different from Epithrella by a variety of features, but superficially similar because of presence of numerous hairs on the upper side of the body. Medvedev (1993a) proposed to separate Epithrella from Livolia by the "densely pubescent upperside and numerous setae on the vertex" (page 17). Later Medvedev (1996) synonymized Orthaltica bakeri Konstantinov, 1995 with Epithrella philippina Medvedev, 1993 (Medvedev 1996). Dorsal pubescence alone 
should never be considered a character to justify generic status in flea beetles. Middle Asian Psylliodes pubipennis Lopatin is the only species of Psylliodes with dorsal pubescence. It is still a Psylliodes, and nobody ever attempted to erect a genus for it. The same is true for a Caucasian Longitarsus pubescens Weise. Epithrella philippina is still a Orthaltica in all characters except short dorsal pubescence (Figs. 78, 80).

Describing Livoliella, Medvedev (1997) compared it to Livolia and wrote the following: "This genus practically agrees with all characters of the genus Livolia and differs from the latter only in the absence of basal groove on prothorax. All but one species of Livolia have basal groove very distinct and deep; the Australian L. vestita Baly, 1877 has this groove rather shallow, but clear enough" (page 101). Clearly, Livolia sensu Medvedev is polymorphic regarding the presence of the groove on pronotum. Study of the paratype of Livolia sulcicollis shows that basal part of its pronotum has a few small indentations near the lateral margins.

Orthaltica, Epithrella, and Livoliella share the following important characters: vertex covered with punctures bearing long setae; antennal calli narrow, oblique and connected presenting the appearance of "V"; anterofrontal ridge flat (Figs. 76, 78, 79); pronotum with strong punctures; lateral margin of pronotum with small projections bearing characteristic setiferous pores (Fig. 80); elytral punctures regularly arranged, interstices more or less convex, lateral sides of elytron highly convex (Fig. 75), epipleuron subvertical, humerus strongly raised, with depression posteriorly. All the above genera lack a metafemoral spring as well as metafemoral spine at the apex (Fig. 77). They also share similar male and female genitalia.

Material examined:

Livoliella luzonica: Paratype 1 female, 1) Philippines, Sadsadan, 1,880 m, Bontoc Prov., Luzon, June 1, 1977, M. Sato leg.; 2) Paratype Livoliella luzonica m. L. Medvedev det. 1997 (LMCM).

Livolia carolina (Chujo): 1 female, 1) Palau Is. Babelthuap I. Ngarard VII-16-53; 2) M-6362; 3) J. W. Beardsley collector; 4) Livolia carolina (Chujo) G. A. Samuelson det. 1970 (1 BPBM). female 1) Koror (NE) 40 m, limestone ridge Palau. XII-14-62; 2) Caroline Is., Pac. Sci. Bd. J. L. Gressitt; 4) Livolia carolina (Chujo) G. A. Samuelson det. 1970 (1 BPBM).

Orthaltica borneoensis: 1 female, 1) Borneo: Sabah, Mt. Kinabalu, N. P. Summit Trail, 2,050 m, IV-26-87; 2) Beating foliage D. E. Bright collector; 3) Orthaltica borneoensis det. A. Konstantinov (USNM).

Orthaltica copalina: 1 male, Iowa, Polk Co, W. Saylorville Lk. June 21-30, 1984, R. H. Schieferstein (USNM).

Orthaltica philippina: Paratype 1 female, 1) Imugin, N. Viskaya, Baker; 2) 8640; 3) Paratype Orthaltica bakeri Konstantinov (USNM).

\section{Phygasoma Jacoby, 1898}

(Figs. 81-86)

Phygasoma Jacoby, 1898: 379 (type species Phygasoma borneoense Jacoby, 1898, by monotypy).

Chabriosoma Chen, 1934a: 69 (type species Chabriosoma thoracicum Chen, 1934, by original designation). New synonym

Describing Chabriosoma, Chen (1934a) compared it to Phygasoma. He proposed the following two characters to separate them: in Chabriosoma the "interantennal space broad, even"... and "posterior margin of prosternum 


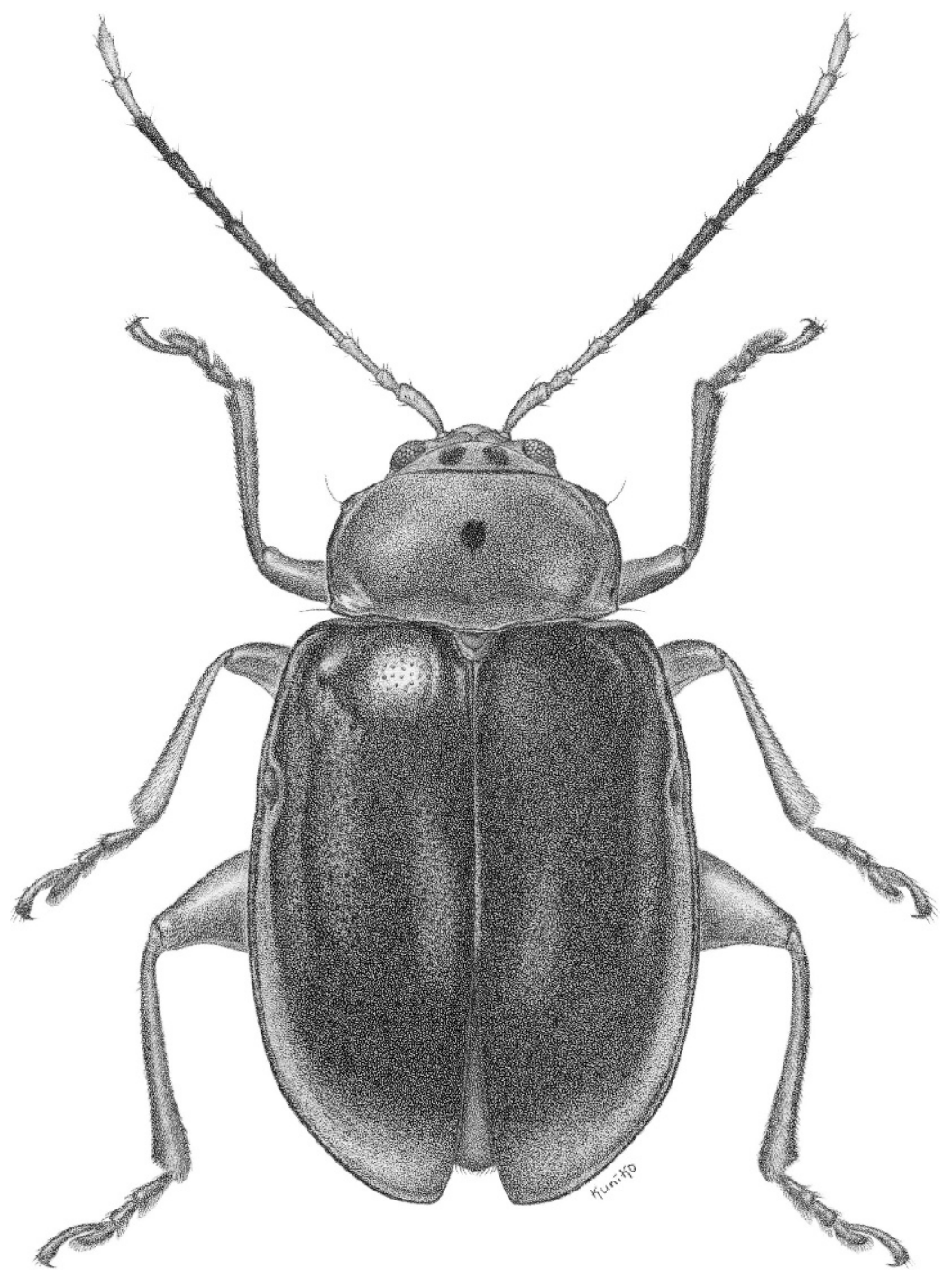

Fig. 81. Phygasoma thoracicum, habitus.

rounded at each side"; in Phygasoma "interantennal space much narrower, channelled".. and "posterior margin of prosternum produced at each side." (p. 70). Careful examination of the type specimens of both taxa could not confirm the above character states. In fact, heads and intercoxal prosternal processes of both type species are identical (Figs. 82, 83, 85). One possible explanation for this could be that Chen's concept of Phygasoma was incorrect. His new species Phygasoma castaneum described in the same paper (Chen 1934a) (of which we also examined a paratype) is not congeneric with Phygasoma borneoense. 

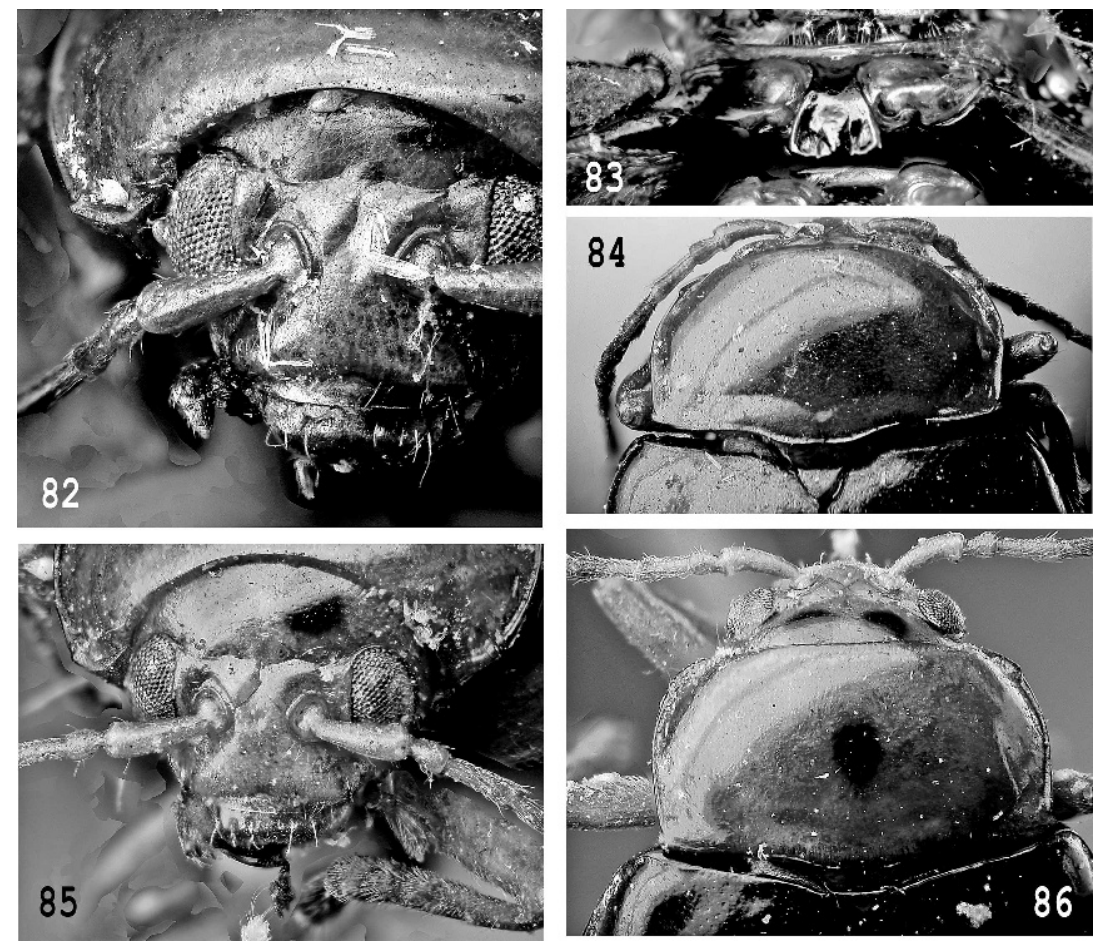

Figs. 82-86. Details of morphology of Phygasoma species. 82) P. borneoense, head; 83) $P$. borneoense, prosternum; 84) $P$. borneoense, pronotum; 85) $P$. thoracicum, head; 86) $P$. thoracicum, prosternum.

Material examined:

Chabriosoma thoracicum: Syntypes 1 male, 1 female, 1) Borneo, Kina Balu; 2)

Whitehead; 3) Fry Coll. 1905 100.; 4) Cotype (BMNH).

Phygasoma borneoense: Syntype 1 female, 1) Kina Balu; 2) $2^{\text {nd }}$ Jacoby Coll.; 3)

Type 19368; 4) Phygasoma borneoensis Cotype Jac. (BMNH).

Phygasoma castaneum: Syntype 1 female, 1) Cotype; 2) Quop. W. Sarawak. G. E.

Bryant, III. 1914; 3) G. Bryant Coll. 1919147 (BMNH).

\section{Phyllotreta Chevrolat, 1836}

(Figs. 87-93)

Phyllotreta Chevrolat in Dejean, 1836: 391 (type species Chrysomela brassicae Fabricius, $1787=$ P. exclamationis Thunberg, 1784, Europe, designated by Chevrolat, 1845).

Letzuana Chen, 1934b: 340 (type species Letzuana depressa Chen, 1934, by monotypy). New synonym

Proposing Letzuana, Chen (1934b) suggested that it can be separated from all flea beetle genera based on the "very short ... and not dilated behind" intercoxal prosternal process. He suggested that it shares this intercoxal prosternal process 


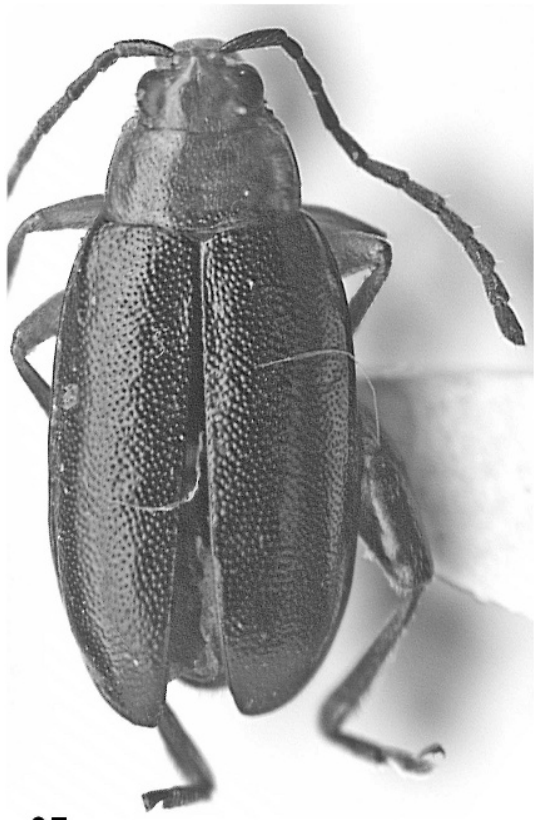

87

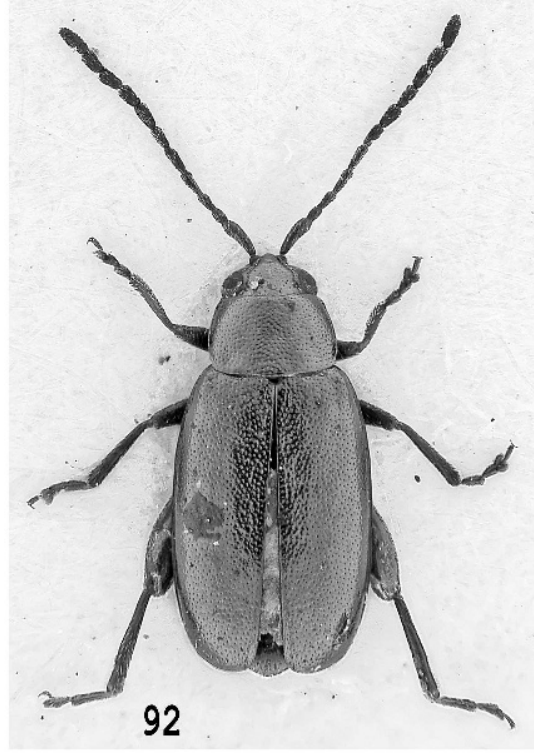

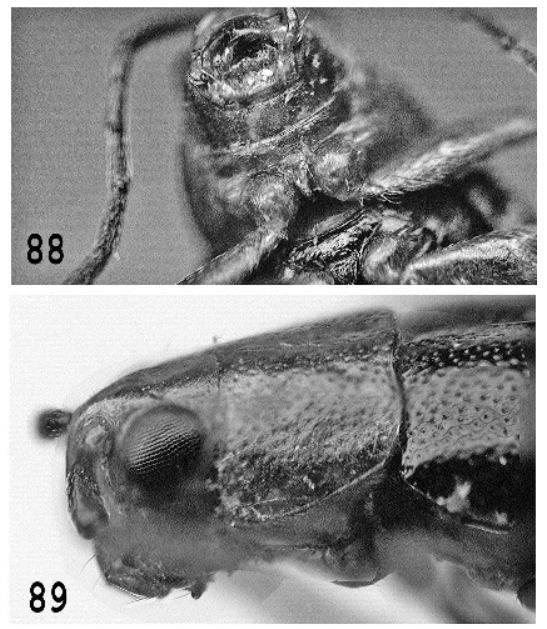
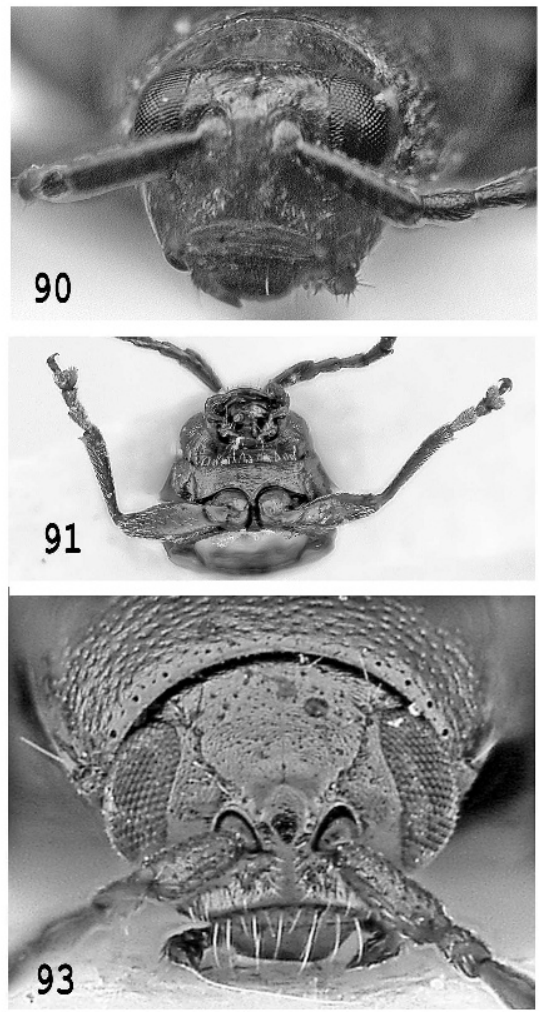

Figs. 87-93. Details of morphology of Phyllotreta species. 87) P. depressa, habitus; 88) $P$. depressa, prosternum; 89) $P$. depressa, head in lateral view; 90) $P$. depressa, head in frontal view; 91) $P$. procera, prosternum; 92) $P$. depressa, habitus; 93) $P$. depressa, head. 
with Letzuella Chen and Laotzeus Chen, from which it is easily separated based on the variety of head characters (Figs. 89, 90).

Comparison of Letzuana depressa with several Phyllotreta species reveals that it shares all the synapomorphies of Phyllotreta, including general body shape (Figs. 87, 92), head (Figs. 89, 90, 93), most of thoracic structures (Figs. 88, 91) and even male genitalia. The short intercoxal prosternal process is also known to exist in Phyllotreta (for example another yet undescribed south Indian species). Based on all of these similarities, we synonymize Letzuana with Phyllotreta.

Material examined:

Letzuana depressa: Holotype 1 male, 1) Pondichery, ? Bosc; 2) Museum Paris, Coll. E. Fleutiaux; 3) type; 4) Letzuana depressa m. S. H. Chen det. $(\mathrm{MNHN})$.

Phyllotreta sp.: 1 male, South India, Western Ghats, Karnataka, env. Madikeri,

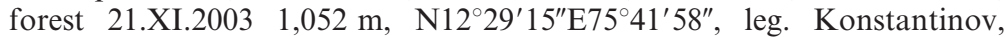
Prathapan, Saluk (USNM).

Phyllotreta procera: 1 female. 1) Georgia, Vashlavanskii zapovednik, 15.V.1975, I. K. Lopatin, Crambe sp. (USNM).

Phyllotreta praticola Weise: 2 males, 3 females, Kirgizstan, Inn. Tien-Shan Naryn river valley, $13 \mathrm{~km}$ SEE Aktal, Artylysh R., 1,750-2,050 m, $41^{\circ} 23^{\prime} \mathrm{N}$ $75^{\circ} 12^{\prime}$ E, 02.VI.2005 S. Saluk leg (USNM)

\section{Sphaeroderma Stephens, 1831}

(Figs. 94-97)

Sphaeroderma Stephens, 1831: 328 (type species Altica testacea Fabricius, 1775, by subsequent designation of Maulik, 1926).

Kimotoa Gruev, 1985: 152 (type species Argopus splendens Gressitt \& Kimoto, 1963, by original designation). New synonym

Describing Kimotoa, Gruev (1985) compared it with Sphaeroderma, Argopus Fischer and Parargopus Chen. The only character that Gruev (1985) uses to separate Kimotoa from Sphaeroderma is the length of the fourth antennomere. It is "much longer than 2 and 3 together" in Kimotoa. Argopus and Parargopus are obviously different from Kimotoa and Sphaeroderma.

Kimotoa is inseparable from Sphaeroderma by any important character. They have similar body shape (Fig. 94), general structure of the head (Figs. 95, 96), legs, and aedeagus: antennal calli subquadrate and delimited by weak sulci and triangular anterior ends entering into interantennal space; orbit narrower than antennal socket; orbital sulcus distinct; frontal ridge widening anteriorly; pronotum transverse, anteriorly narrower than posteriorly, posterior margin weakly lobed in middle, anterior callosity wider than long (Fig. 97); elytral epipleuron broad, subhorizontal; all tibiae widening distally; metatibia convex proximally, gradually turning concave distally, with a longitudinal ridge. We consider modifications of antennae insufficient to treat Kimotoa as a valid genus.

Material examined:

Argopus splendens: Holotype 1 male, 1) Pres. by Com. Inst. Ent. B.M. 1951-209;

2) China, Prov. Yunnan, Vallis flumin., Soling-ho; 3) Kimotoa splendens (Gres. et Kim.) comb. nov.; 4) Kimotoa splendens (Gres. et Kim.) comb. nov.; 5) Type species det. B. Gruev (BMNH).

Sphaeroderma testaceum: 1 male, 1 female, Belarus, Nalibokskaya Puscha, 19.VIII.1985, S. A. Matusevich (USNM). 

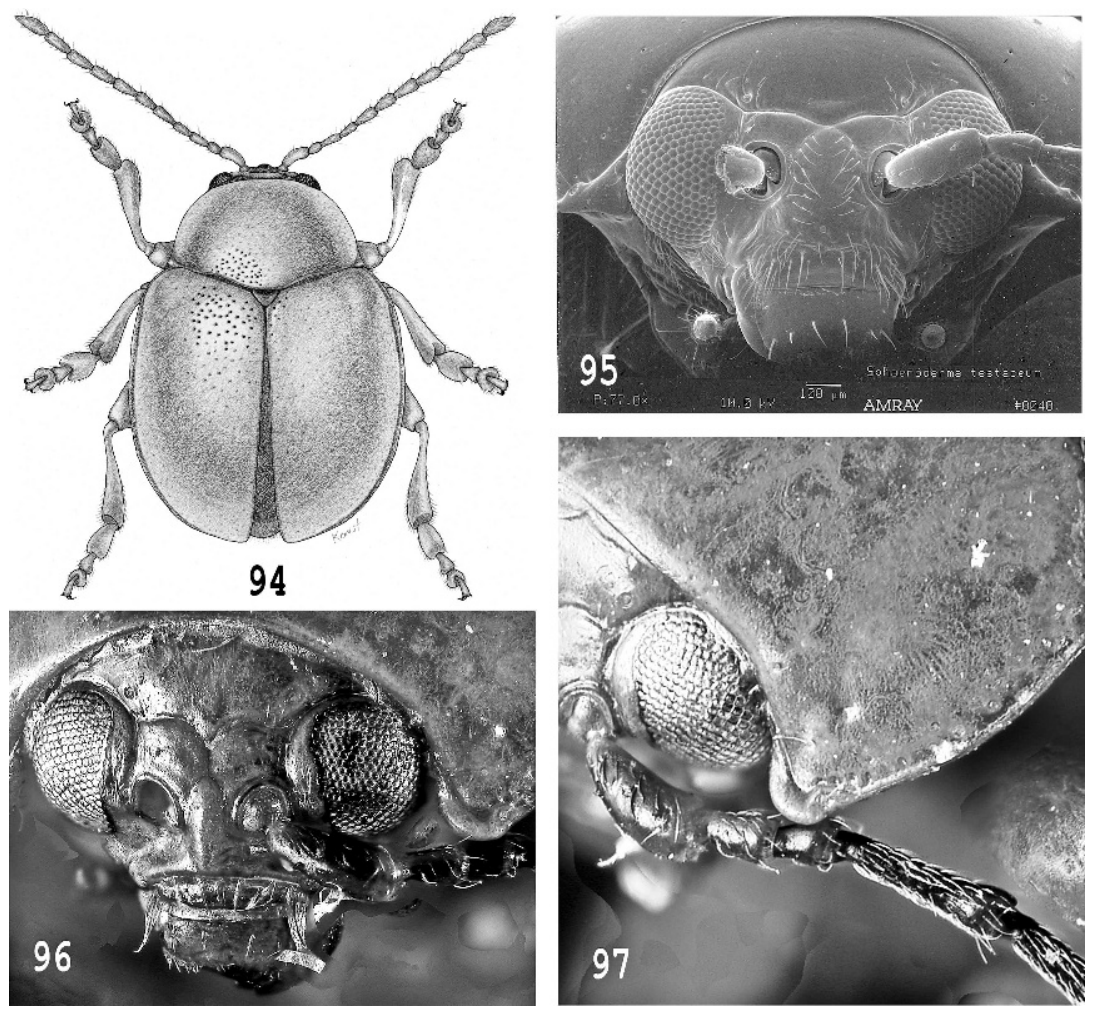

Figs. 94-97. Details of morphology of Sphaeroderma species. 94) S. testaceum, habitus; 95) $S$. testaceum, head; 96) $S$. splendens, head; 97) $S$. testaceum, detail of pronotum.

Sphaeroderma fuscicorne Baly: 1 male, Russia, Far East, Ussuriiski zapovednik, 6.VII.1985, leg. A Pisanenko (USNM).

Sphaeroderma balyi Jacoby: 1 female, Russia, Kunashir Island, Tret'yakovo, 4.VII.1985, leg. S. Saluk (USNM).

\section{Trachytetra Sharp, 1886}

(Figs. 98-104)

Trachytetra Sharp, 1886: 449 (type species Phyllotreta rugulosa Broun, 1880, by original designation).

Amydus Chen, 1935: 76 (type species Amydus castaneus Chen, 1935, by monotypy). New synonym

Monodaltica Bechyne 1955: 509 (Monodaltica guineensis Bechyne, 1955, by original designation). New synonym

Trachyaphthona Heikertinger, 1924: 34 (type species Aphthona sordida Baly, 1874, Japan, by monotypy). New synonym

Typhodes Samuelson, 1984: 32 (type species Typhodes aetherius Samuelson, 1984, by original designation). New synonym 

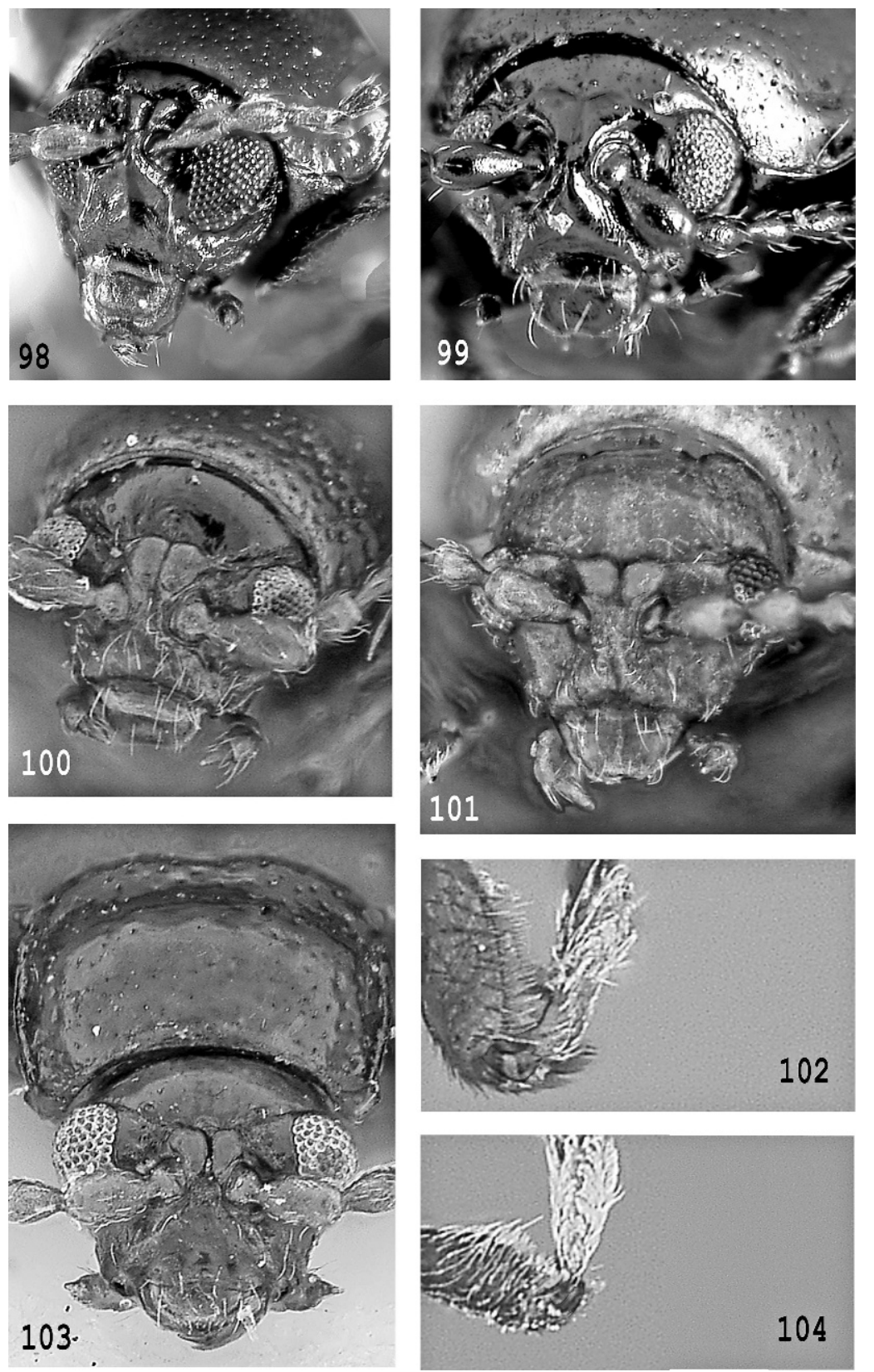

Figs. 98-104. Details of morphology of Trachytetra species. 98) T. guineensis, head; 99) $T$. aetheria, head; 100) $T$. sordida, head; 101) $T$. castanea, head; 102) $T$. guineensis, apex of the metatibia; 103) $T$. obscura, head; 104) $T$. nigra, apex of the metatibia. 
Zipangia Heikertinger, 1924: 39 (type species Haltica obscura Jacoby, 1885, by monotypy).

Proposing Monodaltica, Bechyne (1955) mentioned that it has most of the characters of Aphthonini, but is similar to Dibolia Latreille by the metatibial spur being relatively wide with two sharp angles. However, the metatibial spur of Monodaltica is more similar to the spur of Trachyaphthona sordida than to one of Dibolia (Figs. 102, 104), and its apex is slanted and has one sharp angle and one fairly obtuse. That leaves no characters to separate Monodaltica from Trachyaphthona.

In the original description (Chen 1935), Amydus is compared to Pseudaphthona Jacoby, with which it has very little in common. In all features, Amydus is inseparable from Trachyaphthona (Fig. 101), except for the lack of a humeral calli which is a result of winglessness.

Trachytetra is inseparable from Trachyaphthona, but being an older name it should be treated as a senior synonym.

Proposing Typhodes, Samuelson compared it to Trachytetra and suggested to differentiate it "by ... abdominal sternum 1 as long as or longer than the remaining sterna, instead of distinctly shorter" (Samuelson 1984). However the long first abdominal sternite is not unique for Typhodes, it also occurs in some flightless species of Trachyaphthona. As all other genera under consideration here, Typhodes has a typical Trachyaphthona head (Figs. 98-101, 103), legs, pronotum (Fig. 103) and elytra, and it is considered as a synonym of Trachytetra.

Zipangia was already synonymized with Trachyaphthona (Ohno 1961), but was treated separately (Konstantinov and Vandenberg 1996) based on the presence of the impression on the pronotum. However, a shallow, poorly differentiated impression is a variable character in this group. Otherwise, Zipangia is inseparable from Trachyaphthona and Trachytetra.

Material examined:

Amydus castaneus: Holotype 1 male, 1) Mus. Nat. Hist., Harmand, Sikkim, 1890;

2) type; 3) Amydus castaneus m. S. H. Chen det. (MNHN)

Monodaltica guineensis: 1 female, 1) Exped. Mus. G. Frey, Franz. Guinea 1951, W. Afr. leg. Bechyne; 2) Foufa Djallon, Dalaba 1,200 m, 22.6.51; 3) F. Monros Collection 1959; 4) Monodaltica guineensis Bech. (USNM).

Trachyaphthona sordida: 1 female, Japan, Takao-san, 2.VII.1961 (USNM). 1 male, Japan, Ofune, 14.VI.36, Zhenzhurist (USNM).

Trachytetra frontalis: 1 male, 1 female. 1) New Zealand, North Is Huia, 1727.XI.1981, H. \& A. Howden (USNM).

Typhodes aetherius: Paratypes 1 female, 1 male, 1) New Guinea: NE nr. Lake Aunde, 3,350 m, 12.VI.1967; 2) G. A. Samuelson Collector, Bishop Museum; 3) Paratype Typhodes aetherius Samuelson (USNM).

Zipangia obscura: 1 female, 1 male, Japan, Nikko, 15.V.54 (USNM). 1 female, 1 male, Japan, Kyushu (USNM).

\section{Acknowledgments}

We thank D. Nickle, A. L. Norrbom and J. Prena (Systematic Entomology Laboratory, ARS, USDA, Washington, DC), and A. K. Tishechkin (Department of Entomology, Smithsonian Institution, Washington, DC) for reviewing earlier versions of this manuscript and providing valuable suggestions. We thank the following artists for the following habitus illustrations, E. Roberts (Systematic Entomology Laboratory, ARS, USDA, Washington, DC) for Fig. 1, Kuniko 
Arakawa (Moriya, Japan) for Figs. 12, 19, 26, 64, 81, and Linda Lawrence (Systematic Entomology Laboratory, ARS, USDA, Washington, DC) for Fig. 7.

\section{Literature Cited}

Baly, J. S. 1862. Descriptions of new genera and species of Phytophaga. Journal of Entomology 1:450-459.

Baly, J. S. 1876. Descriptions of new genera and species of Halticinae. Transactions of the Entomological Society of London 3:433-449.

Baly, J. S. 1877. Descriptions of new genera and of uncharacterized species of Halticinae. Transactions of the Entomological Society of London 4:157-184, 283-323.

Bechyne, J. 1955. Über die westafrikanischen Alticiden. Entomologische Arbeiten aus dem Museum G. Frey, Tutzing 6(2):486-568.

Doeberl, M. 1996. Beitrag zur Kenntnis der Alticinen der Orientalischen Region (Coleoptera, Chrysomelidae, Alticinae). Entomologische Blätter 92:110-115.

Chen, S. H. 1933a. Chrysomelidae (Coleoptera) nouveaux de l'Asie tropicale. 1 note. Bulletin du Muséum Paris 5(5):381-388.

Chen, S. H. 1933b. Chrysomelidae (Coleoptera) nouveaux de l'Asie tropicale. 2e note. Bulletin du Muséum Paris 5(5):449-456.

Chen, S. H. 1933c. Descriptions de deux Halticinae nouveaux de la Chine et du Japon. Bulletin de la Société Entomologique de France 38:143-144.

Chen, S. H. 1934a. On some species of Chrysomelidae (Col.) in the British Museum (continued). Stylops 3(4):6672-7378.

Chen, S. H. 1934b. Revision of the Halticinae (Col. Chrysomelidae) of Yunnan and Tonkin. Sinensia 5(3, 4):225-393.

Chen, S. H. 1935. Coleoptera Halticinae de la collection du Museum recueillis par le Dr. Hammond au Sikkim. Bulletin de la Société Entomologique de France 40:75-80.

Chevrolat, L. 1836. In: Catalogue des Coléoptères de la collection de M. (P. E. Dejean, editor). le Comte Dejean, Paris. 443 pp.

Chevrolat, L. 1845. In: d'Orbigny, Dictionaire Universal d'Histoire Naturelle. Paris. 6. $792 \mathrm{pp}$.

Chûjô, M. 1935. Studies on the Chrysomelidae in the Japanese Empire (VIII) subfamily Halticinae 1. Transactions of the Natural History Society of Formosa 145:354-369.

Chûjô, M. 1937. Studies on the Chrysomelidae in the Japanese Empire (VIII) subfamily Halticinae 8. Transactions of the Natural History Society of Formosa 162:52-58.

Crotch, G. R. 1873. Materials for the study of the Phytophaga of the United States. Proccedings of the Academy of Natural Sciences of Philadelphia 25:19-83.

Gressitt, J. L., and S. Kimoto. 1963. The Chrysomelidae (Coleopt.) of China and Korea Part 2. Pacific Insects Monograph 1B:301-1026.

Gruev, B. 1985. Two new taxa of Alticinae from China (Coleoptera, Chrysomelidae). Entomological Review, Japan 40(2):125-127.

Heikertinger, F. 1924. Die Halticinengenera der Palaearktis und Nearktis. Bestimmungstabelle. Koleopterologische Rundschau 9:25-70.

Heikertinger, F., and E. Csiki. 1940. Chrysomelidae: Halticinae. In: Coleopterorum Catalogus (W. Junk, editor). Pars 166 et 169. Gravenhage. 337-635 pp.

Jacoby, M. 1884. Priostomus nov. gen. (Halticinae). Stettiner Entomologische Zeitung 45:185-186.

Jacoby, M. 1885. Descriptions of new genera and species of Phytophagous Coleoptera from the Indo-Malayan and Austro-Malayan subregions, contained in the Genoa Civic Museum. Second Part. Annales del Museo Civico di Storia Naturale. Ser. 2(2):21-76.

Jacoby, M. 1887a. Descriptions of some new genera and species of Phytophagous Coleoptera contained in the Leyden Museum. Notes Leyden Museum 9:229-244.

Jacoby, M. 1887b. Descriptions of the Phytophagous Coleoptera of Ceylon, obtained by Mr. George Lewis during the years 1881-82. Proceedings of Zoological Society. London 5:65-119.

Jacoby, M. 1893. Descriptions of some new genera and new species of Halticidae. Transaction of the Entomological Society, London 2:145-158. 
Jacoby, M. 1898. New species of Phytophagous Coleoptera from Australia and the Malayan regions. Annales de la Societe Entomologique de Belgique 42:350-380.

Jacoby, M. 1899. Descriptions of the new species of Phytophagous Coleoptera obtained by Dr. Dohrn in Sumatra. Entomologische Zeitung 4(10-12):259-285.

Jacoby, M. 1900. New species of Indian Phytophaga principally from Mandar in Bengal. Memoirs, Société Entomologique de Belgique 7(3):95-140.

Jacoby, M. 1903. Descriptions of new genera and species of phytophagous Coleoptera obtained by Mr. H.- L. Andrewes and Mr. T.-R.-D. Bell at the Nilgiri Hills and Kanara. Annales de la Société Entomologique de Belgique 47:80-128.

Jacoby, M. 1903. A further contribution to our knowledge of African Phytophagous Coleoptera, Part II. Transaction of the Entomological Society, London 1903:15.

Jacoby, M. 1904. Another contribution to Indian phytophagous Coleoptera. Annales de la Société Entomologique de Belgique 48:380-406.

Kimoto, S., and H. Takizawa. 1994. Leaf Beetles (Chrysomelidae) of Japan. Tokai University Press, $539 \mathrm{pp}$.

Konstantinov, A. S. 1995. New species of Clavicornaltica and Orthaltica from the Australian and Oriental Regions (Coleoptera: Chrysomelidae: Alticinae). Zoosystematica Rossica 3(2):283-288.

Konstantinov, A. S. 1998. Revision of the Palearctic species of Aphthona Chevrolat and cladistic classification of the Aphthonini (Coleoptera: Chrysomelidae: Alticinae). Memoirs on Entomology, International, Associated Publishers, Gainesville. 429 pp.

Konstantinov, A., and N. Vandenberg. 1996. Handbook of Palearctic flea beetles (Coleoptera: Chrysomelidae: Alticinae). Contributions on Entomology, International 1(3):237439.

Lea, A. M. 1917. Notes on some miscellaneous Coleoptera with descriptions of new species. Part III. Transactions of Royal Society of South Australia 41:121-320.

Maulik, S. 1926. Coleoptera. Chrysomelidae (Chrysomelinae and Halticinae). In: The fauna of British India including Ceylon and Burma. (A. E. Shipley, editor). Taylor and Francis, London. 442 pp.

Maulik, S. 1928. New chrysomelid beetles from India with a note on the scales of Coleoptera. Proceedings of the Zoological Society of London 1:151-161.

Maulik, S. 1931. Coleoptera, Chrysomelidae: Eumolpinae, Galerucinae and Halticinae. The Transactions of the Linnean Society of London 2. Zoology 8:241-260.

Medvedev, L. N. 1984. Chrysomelidae from the Nepal Himalayas, 1. Alticinae (Insecta: Coleoptera). Senckenbergiana Biologica 65:47-63.

Medvedev, L. N. 1990. Chrysomelidae from the Nepal Himalayas, II) (Insecta: Coleoptera). Stuttgarter Beiträge zur Naturkunde Ser. A (Biologie) 453:1-46.

Medvedev, L. N. 1993a. Alticinae of the Philippine Islands (Coleoptera, Chrysomelidae). Part 2. Russian Entomological Journal 2(3-4):41-58, 2(5-6):11-32.

Medvedev, L. N. 1993b. New species of Chrysomelidae from South Asia from the Natural History Museum in Basel. Entomologica Basilensia 16:359-376.

Medvedev, L. N. 1996. New data on Alticinae (Coleoptera, Chrysomelidae) from the Philippines. Russian Entomological Journal 5(1-4):65-83.

Medvedev, L. N. 1997. New and interesting Chrysomelidae (Coleoptera) from the Philippines collected by Dr. M. Sato. Japanese Journal of Systematic Entomology 3(1):99-104.

Medvedev, L. N. 2004. A revision of the genus Chaloenus Westwood, 1861 (Coleoptera: Chrysomelidae: Alticinae) from Oriental region. Russian Entomological Journal 13(4):245-252.

Motschulsky, V. 1860. Insectes des Indes orientales, et de contrees analogues. Etudes Entomologiques 8:25-118.

Ohno, M. 1961. On the species of the genus Trachyaphthona Heikertinger and the new genus Sphaeraltica (Coleoptera, Chrysomelidae). Studies of the flea-beetles of Japan (3). Bulletin, Department of Liberal Arts Toyo University 2:73-91.

Patra, B., and S. Bera. 2007. Herbivore damage to ferns caused by a Chrysomelid beetle from lower Gangetic plains of West Bengal, India. American Fern Journal 97(1):19-29. 
Samuelson, G. A. 1973. Alticinae of Oceania (Coleoptera: Chrysomelidae). Pacific Insects Monograph 30, 165 pp.

Samuelson, G. A. 1984. Plant associated Alticinae from the Bismarck range, Papua New Guinea (Coleoptera: Chrysomelidae). Esakia 21:31-47.

Scherer, G. 1969. Die Alticinae des Indischen Subkontinentes (Coleoptera - Chrysomelidae). Pacific Insects Monograph 22, $251 \mathrm{pp}$.

Scherer, G. 1974. Review of North American species of Orthaltica with new generic synonymy (Coleoptera: Chrysomelidae: Alticinae). The Coleopterists Bulletin 28(2):65-72.

Scherer, G. 1979. Ergebnisse der Bhutan-Expedition 1972 des Naturhistorischen Museums in Basel. Coleoptera: Fam. Chrysomelidae, Subfa. Alticinae (1. Teil). Entomologica Basilensia 4:127-139.

Scherer, G. 1989. Ground living flea beetles from the Himalayas (Coleoptera, Chrysomelidae, Alticinae). Spixiana 12(1):31-55.

Sharp, D. 1886. On New Zealand Coleoptera, with description of new genera and species. Transactions Royal Dublin Society 3(2):351-456.

Stephens, J. F. 1831. Illustration of British entomology. IV. Mandibulata, London. 408 pp.

Weise, J. 1887. Neue sibirische Chrysomeliden und Coccinelliden nebst Bemerkungen über früher beschriebene Arten. Archiv für Naturgeschichte 53:192-209.

Westwood, J. O. 1862. Description and figures of a new genus and species of Gallerucidae. Journal of Entomology descriptive and geographical 1:216-218.

(Received 29 December 2007; accepted 13 May 2008. Publication date 16 October 2008.) 